Columbia Business School
Center on Japanese Economy and Business

CENTER ON JAPANESE ECONOMY AND BUSINESS

日本经济经営研究所

Working Paper Series

October 2014, No. 339

\title{
Japanese Monetary Policy and International Spillovers
}

Robert Dekle and Koichi Hamada

This paper is available online at www.gsb.columbia.edu/cjeb/research

COLUMBIA UNIVERSITY IN THE CITY OF NEW YORK 


\title{
Japanese Monetary Policy and International Spillovers
}

\author{
Robert Dekle and Koichi Hamada
}

Department of Economics

USC

Department of Economics

Yale University

\section{August 2014}

All opinions expressed in this paper are strictly those of the authors and should not necessarily be attributed to any organizations the authors are affiliated with. We thank participants at the University of San Francisco, the Development Bank of Japan, the Policy Research Institute of the Japanese Ministry of Finance and the JIMF-USC Conference for helpful comments. We especially thank Takeo Hoshi, the discussant and Menzie Chinn, the editor, for helping us improve this paper. 


\begin{abstract}
The Japanese currency has recently weakened past 100 yen to the dollar. The reason for the recent depreciation of the yen is the expectation of higher inflation in Japan, owing to the rapid projected growth in Japanese base money, the sum of currency and commercial banking reserves at the Bank of Japan.

We show through our empirical analysis that recent expansionary Japanese monetary policies have generally helped raise U.S. GDP, despite the appreciation of the dollar.
\end{abstract}

\title{
1 Introduction.
}

The Japanese currency has recently weakened past 100 yen to the dollar. The reason for the recent depreciation of the yen is the expectation of higher inflation in Japan, owing to the rapid projected growth in Japanese base money, the sum of currency and commercial banking reserves at the Bank of Japan. Under a flexible exchange rate regime, national monetary policies are the basic determinant of exchange rates among nations.

The recent depreciation of the yen has led to the criticism that Japan is engaging in a "currency war," that Japan is stimulating its domestic demand at the expense of its trading partners. ${ }^{1}$ In general, however, the expansion of the money supply or the credible announcement of a higher inflation target does not necessarily constitute a currency war. We show in a two-country money game under flexible exchange rates, that uncoordinated monetary expansion does not lead the world into a undesirable disequilibrium, regardless of whether the monetary expansion has positive or negative spillovers on other countries. ${ }^{2}$

The pareto-optimality criterion holds whether the spillovers from say a Japanese monetary expansion are negative or positive, whether they lower or raise U.S. GDP. In real world international relations, however, it would seem better if the monetary expansion in one country is accompanied by positive spillovers on the other country. In the real world, an appreciating yen-dollar rate may shift employment from the U.S. to Japan. This would hurt and upset the U.S., possibly damaging U.S.-Japan relations if continued. It is certainly better if Japanese expansionary monetary policies are accompanied not only by a depreciating yen, but also expanding Japanese GDP and asset (equity and bond)

\footnotetext{
${ }^{1}$ Some conference participants have pointed out that defining a "currency war" solely as a negative GDP spillover is too narrow. A broader definition of a "currency war" should include when a particular constituent in one country is hurt by a foreign currency depreciation, and the country retailates because ot political pressures from the constituent. For example, if the U.S. auto industry is hurt by a yen depreciation, the U.S. may retaliate by imposing tariffs on Japanese auto imports.

${ }^{2}$ Our analysis, which follows from Hamada (1985) and Hamada and Okada (2009) is echoed in Korinek (2013) who argues in an application of the theory of the second best, that if there is an aggregate demand externality, say of insufficient demand, then the country suffering from that externality should enact policies to lessen the effects of that insufficient demand, such as an expansionary monetary policy that depreciates the exchange rate, even if that should mean than another country is hurt by its own appreciating currency.
} 
prices. If the rising Japanese GDP and asset prices help raise U.S. GDP, then the U.S. will have less reason to get upset. The main objective of this paper is to show whether Japanese expansionary monetary policies raise or lower U.S. GDP, whether Japanese expansionary monetary policy has positive spillovers on the U.S..

We show in our two country (U.S.-Japan) vector autoregressions that an expansion in Japanese broad money, while depreciating the yen, will tend to raise Japanese GDP and asset prices. ${ }^{3}$ Although expansionary Japanese monetary policies may hurt U.S. GDP in the short-run, in the medium- to long-runs, the increase in Japanese GDP will tend to raise U.S. GDP. Thus, Japanese expansionary monetary policies should be welcomed by the U.S. We show in a multicountry VAR model (GVAR-Global VAR), that expansionary monetary policies in Japan will tend to also raise the GDPs of Japan's smaller (nonChina) neighbors in the medium- to the long-runs, while hurting their GDPs in the short-run.

While there have been academic analysis of the effects of Abenomics monetary policies on the domestic Japanese economy (Hoshi, 2014; Hausman and Weiland, 2014; Michelis and Iacoviello, 2014; Rogers and Wright, 2014), our paper is the first to empirically examine the spillover effects of the recent Japanese monetary expansions on the U.S. economy.

\section{Monetary Interdependence in a Two-country}

\section{World.}

Let us introduce a world economy where prices are sticky and the two countries target a point on the Phillips curve, $\mathrm{y}_{g}^{i}\left(\pi^{i}\right)$, where $\mathrm{i}=\mathrm{J}$ (Japan) or the U.S., and $\pi$ is the inflation rate and $\mathrm{y}_{g}$ is the output gap.

Define excess money creation of the two countries as:

$$
\begin{aligned}
& \mathrm{x}^{J}=\frac{\Delta m^{J}}{m^{J}}-k \frac{\Delta y_{g}^{J}}{y_{g}^{J}} \\
& \mathrm{x}^{U . S .}=\frac{\Delta m^{U . S .}}{m^{U . S .}}-k \frac{\Delta y_{g}^{U . S .}}{y_{g}^{U . S .} .}
\end{aligned}
$$

Excess money creation refers to the money created in a country in excess of the increase in domestic money demand.

Inflation in the two countries can then be written as:

$$
\begin{aligned}
& \pi^{J}=x^{J}+\nu\left(x^{J}-x^{U . S .} .\right. \\
& \pi^{U . S .}=x^{U . S .}+\gamma\left(x^{U . S .}-x^{J}\right),
\end{aligned}
$$

\footnotetext{
${ }^{3}$ Since 1998, when Japan adopted its zero interest rate policy, Japanese monetary policy certainly weakened its grasp on the inflation rate and output. However, the quantitative expansion of money can impact the economy, by way of an increase in Tobin's q (by raising stock market values), by the credit accelerator effect, and by depreciating the nominal exchange rate.
} 
where $-1<\gamma<1$. That is, $\gamma$ can be positive of negative. A positive $\gamma$ implies that excess money creation abroad will lower the domestic inflation rate, say, owing to a domestic currency appreciation. This is the case of a "beggar-thyneighbor" monetary policy. From the Phillips curve relation, an expansion in foreign monetary policy with negative spillovers on the partner country will lower the domestic output gap for every inflation rate in the domestic economy.

A negative $\gamma$, on the other hand, implies that excess money creation abroad will raise the domestic inflation rate. From the Phillips curve relation, an expansion in foreign monetary policy will raise the domestic output gap for every inflation rate in the domestic economy. This can occur when foreign money creation raises foreign output or asset prices so much, that domestic inflation and output will also be raised. For example, Eichengreen and Sachs (1985, 1986) show that the sequence of devaluations in the 1930s led to a recovery of domestic growth and equity markets, resulting in positive spillover effects on other countries, helping the global economies recover.

Suppose that each country targets its own inflation rate (and simultaneously, its accompanying output gap from the above Phillips curve relation). The two countries will then minimize the distance between the actual and the desired inflation rates:

$$
\begin{aligned}
& \left(\pi^{J}-a^{J}\right)^{2}=\left(x^{J}+\gamma\left(x^{J}-x^{U . S .}\right)-a^{U . S .}\right)^{2} \\
& \left(\pi^{U . S .}-a^{U . S .}\right)^{2}=\left(x^{U . S .}+\nu\left(x^{U . S .}-x^{J}\right)-a^{J}\right)^{2}
\end{aligned}
$$

The first-order condition is given by a set of "reaction curves":

$$
\begin{aligned}
& (1+\nu) x^{J}-\gamma x^{U . S .}=a^{J} \\
& -\gamma x^{J}+(1+\gamma) x^{U . S .}=a^{U . S .}
\end{aligned}
$$

The "reaction curves" (1) and (2) are depicted and solved for $0<\gamma<1$ and $1<\gamma<0$ in Figures 1 (a) and 1 (b) respectively. In both cases, the U.S. inflation target is assumed to be higher than the Japanese inflation target, a $\mathrm{a}^{U . S .}>a^{J}$. All points on the reaction curves are bliss points, so their intersection satisfies the pareto-optimality criterion.

In Figure 1(a), the increase in home money will induce the increase of foreign money and vice versa. As each country pursues its own inflation target, the system will converge to a stable ratio of money supplies and therefore a stable exchange rate (as long as $\gamma<1$ ). Note that in this case, even if the expansion of money in Japan has negative spillovers on the U.S., given the pareto optimality criterion, U.S.'s welfare cannot be improved without hurting Japan's welfare. Given that the uncoordinated, competitive equilibrium is pareto optimal, there is no need for the two countries to coordinate their monetary policies.

The incidence of the Lehman crisis and in particular, the drastic quantitative easing in the U.S. and in the U.K. seem to suggest that the initial short-run reaction of the monetary expansion under flexible rates is negative (in terms of GDP) on Japan (as in Figure 1(a)). Otherwise, Japan would not have been driven into a recession after 2009 when the U.S. and the U.K. were expanding 
money drastically. ${ }^{4}$ Indeed in our two-country vector autoregressions, we find that an expansion in U.S. money will lower Japanese GDP in the short-run, through a depreciation of the U.S. dollar.

However, in the medium- to long-runs, we find that the monetary expansion raised the GDPs and the stock markets of the U.S. and the U.K., leading to increased Japanese GDP, from the increased U.S. and U.K. aggregate demands. In terms of our model, in that medium- to long-run case, $\gamma>1$, so Figure $1(\mathrm{~b})$ would apply. ${ }^{5}$

While from a pareto-optimality welfare standpoint, the postive-spillover case (the equilibrium depicted in Figure 1(b)) is no better than the negative-spillover case (the equilibrium depicted in Figure 1(a)), in real world international relations, it would be better if expansionary monetary policies abroad are accompanied not only by a depreciating foreign currency, but also expanding foreign GDP and asset (bond and stock) prices, so that foreign money growth will have positive spillovers, at least in the longer run.

\subsection{Vector Autoregressions of Japanese Monetary Policy,}

\section{1-2013.}

In this paper, we will examine the impact of Japanese monetary policies through vector autoregressions. While it is by now well established that economies should be characterized by dynamic stochastic general equilibrium models, often such models build in either monetary neutrality (real business cycle models) or monetary effectiveness (New Keynesian models). In these highly structural models, there is little scope to examine whether or not Japanese monetary policy has been to able to affect the real economies in Japan and the U.S. in the first place, since the result is already assumed. Moreover, there is yet to be developed, a well accepted quantitative model of monetary policies under the zero lower interest rate bound, or of quantitative easing by the central bank, which both the Bank of Japan and the Federal Reserve have recently engaged in. In this paper, we try to impose as little structure as possible to make the data speak, with regards to the effectiveness of Japanese monetary policies over the entire period of 1971-2013.

It is by now well known that it is difficult to uncover the properties of the underlying dynamic general equilibrium models through vector autoregressions (Chari, Kehoe, and McGratten, 2008; Christiano, Eichenbaum, and Vigfusson, 2006). Still, vector autoregressions can be useful in discerning regularities in the data (Fernandez-Villaverde, Rubio-Ramirez, Sargent, and Watson, 2007 ).

\footnotetext{
${ }^{4}$ In this regard, the Chinese situation today may need more attention. If China reacts to its current subprime-like financial situation by expanding its monetary policy, then Japan may be negatively affected. Japan, however, may be able to undo such a negative impact by further expanding its money supply.

${ }^{5}$ Figure $1(\mathrm{~b})$ is drawn for the special case of $-0.5<\gamma<0$, when the two "reaction curves" intersect in the upper right hand quadrant. See Cooper (1985) for a more formal analysis of this "positive spillover" case of national monetary policies, where a proposal is made for international monetary coordination.
} 
We examine aggregate data from when the U.S. and Japan went off the Bretton Woods system - in 1971-to the recent start of "Abenomics," when Japan embarked on a massive increase in base money. While this 40 year period has been sparked by numerous regime, expectational, and structural changes, we try to (partially) capture these changes through the use of dummy variables and the estimation of the model on different subperiods. We thus have tried different sample periods such as staring the sample in 1980Q1 and 1995Q1, or ending the sample in 1999Q4. ${ }^{6}$

In the U.S., and particularly in Japan, recent monetary policy has been characterized by quantitative easing, which is to allow reserves held by depository institutions far above the required level, while keeping the policy rate close to zero. In principal, at interest rates near zero, the relationship between monetary policy and other variables such as the exchange rate become non-linear.

Researchers have tried to handle such non-linear relationships using nonlinear time series econometrics such as Markov-Switching structural vector autoregressions. For example, in Japan, Fujiwara (2006), Inoue and Okimoto (2008), Kimura and Nakajima (2013) and Hayashi and Koeda (2013) find that the impulse responses of inflation and output to the monetary base is positive.

However, we consider the use of non-linear time series econometrics as beyond the scope of the current paper for the following reasons. First, our shortterm interest rate variable in Japan is the three month interest rate, not the call rate, which is the policy rate. The Japanese three-month interest rate never touches zero and has fluctuated up and down (albeit slightly) even during Japan's quantitative easing period of the early 2000s. Second, impulse response functions that we use extensively in this paper are ill-defined in a nonlinear econometrics framework (Hayashi and Koeda, 2013). And third, the main model that we estimate (in Section 4) is a two country model in which there is likely to be shifting regimes in both countries. None of these authors examine the relationship between the expansion of monetary variables in Japan and the exchange rate or real output in the U.S., the main focus of our paper. Estimation of such two country, multiple-regime models with time series data will quickly run into degrees of freedom problems, especially in maximum-likelihood estimation.

\subsection{Some Graphs.}

Figure 2 depicts the short-term nominal interest rates for Japan and for the U.S. For Japan, for short-term rates, we used the contracted 3-month interest rates on loans and discounts (available from the Bank of Japan). We use these data, rather than the data on overnight call rates, which are directly controlled by the Bank of Japan, because the call rates have had a zero lower bound between

\footnotetext{
${ }^{6}$ Arai and Hoshi (2006) and Hutchison (2004) show that there was a structural break in the money multiplier in the mid-1990s.
} 
2000 and 2006 and again from 2009 onwards. ${ }^{7}$ For the U.S., we use the Federal Funds rate as the short-term interest rate variable. For the U.S. the Federal Funds rate has been nearly zero since only 2009. Since the 1970s, U.S. short rates have almost always been higher than in Japan. Since 1996, Japanese short rates have been nearly zero, with a blip in rates in 2006 when the first period of quantitative easing was dropped. Short-term interest rates were again brought to zero after the late 2000s financial crisis.

Figure 3 examines the relationship between the gap in U.S. and Japanese short-term nominal interest rates and the yen-dollar exchange rate. Interest rate parity suggests that when the gap is large, the yen should be depreciating (the line should be downward sloping), but we can hardly discern such pattern in this simple plot. This lack of a pattern is another example of the well-known failure of the short-term interest rate parity condition. That is, there appears to be no consistent relationship between U.S. and Japanese interest rate differentials and movements in the yen-dollar nominal exchange rate.

Figure 4 depicts the ratio of base money in the U.S. to base money in Japan, from 1971Q2 to 2013Q1. This ratio started to decline from the mid-1980s, showing the desire of the Bank of Japan to reflate the economy after the sharp appreciation of the yen after the Plaza Accord in 1985 (see Hamada and Okada, 2009). Starting at around 1990, the ratio of base monies sharply increased. This is a result of the relative tightening of monetary policy in Japan, as the Bank of Japan tried to burst the real estate bubble of the late 1980s and early 1990s. In the late 1990s, Japan embarked on the first of its quantitative easing programs, and the ratio of base monies declined; this was in spite of relatively loose money in the U.S. Starting in 2006, and then in 2009, the ratio of base monies rose at an unprecedented rate, the second rise owing to the series of quantitative easing programs adopted in the U.S. Very recently the ratio of base monies between Japan and the U.S. started to decline, as Japan sharply increased its base money supply under "Abenomics."

Figure 5 depicts the correlation between the ratios of base monies in the U.S. and in Japan with the nominal yen dollar rate. This figure is the socalled "Soros" diagram, a folk tale in the financial world. The upward tilt in the correlation between the yen-dollar rate and the ratio of base monies on the right hand side of the graph depicts the appreciation of the yen after the 1971 Bretton Woods float to about 1974. This was a movement towards yen-dollar purchasing parity (the yen was undervalued before 1971) after the post-Bretton Woods dollar float. The negative correlation between the ratio of base monies and the exchange rate on the left-hand side are from the post-2006 period. After the massive recent increases in the base money supply in the U.S., the yen sharply appreciated relative to the dollar. Overall, in Figure 4, there appears to be a negative relationship between the ratio of base monies and the yendollar exchange rate. That is, when the base money of Japan grows faster than the base money of the U.S., the yen tends to depreciate. ${ }^{8}$ We confirm this

\footnotetext{
${ }^{7}$ In empirical analysis of Japanese monetary policy since the late $1990 \mathrm{~s}$, it is common to use Japanese three-month treasury bill rate (Ueda, 2009).

${ }^{8}$ This relationship between base money ratios and the exchange rate was first noted in the
} 
relationship between the expansion of base money and the depreciation of the currency in our impulse responses below. ${ }^{9}$

Finally, Figure 6 shows the correlation between the Japanese actual CPI inflation rate and one-year ahead inflation expectations. ${ }^{10}$ The two series move surprisingly close together, although there is a persistent upward bias in household inflationary expectations. As shown in previous studies of Japanese inflationary expectations (Ueda, 2009), households in Japan appear to form their expectations based on actual inflation of goods that they purchase often such as food and electricity, which are impacted by imported food and energy prices. Households tend to see inflation rates as much higher than what they are actually. Still, we find that movements in actual and expected inflation are highly correlated, and that inflation expectations change more quickly than does realized inflation. The correlation between our measure of expected inflation and realized inflation is about 0.57 from 1971 to 2013, and the expected inflation rate leads realized inflation by two to three quarters. Through massive injections of base money and a depreciation of the yen-dollar nominal exchange rate, which should increase imported food and energy prices, "Abenomics" seeks to raise inflationary expectations and thereby actual inflation rates.

\subsection{Japan: Vector Autoregressions of Monetary Policy.}

Here we estimate vector autoregressions using Japanese data. We run vector autoregressions on the output gap, the one year ahead CPI inflation rate, the three month nominal interest rate, one year ahead CPI inflation rate forecast, log base money (currency plus reserves), and the nominal yen-dollar rate, from 1971 Q1 to 2013 Q2. In symbols: $\left\{\mathrm{y}_{g}^{J}, \pi^{J}, m^{J}, i^{J}, \pi^{e}, e\right\}$. ${ }^{11}$ All vector autoregressions include the CPI inflation rate in energy and food as an exogenous variable, since the food and energy CPI index is found in earlier studies to strongly affect the Japanese overall inflation rate (Ueda, 2009). Other vector autoregressions

\footnotetext{
academic literature by Hamada and Okada (2010).

${ }^{9}$ Conference participants have pointed out that monetary bases may not be a useful measure of monetary policy any more, since Central Banks are now buying long term bonds. That there is still a strong positive correlation between a yen appreciation and the ratio of narrow monies in the U.S. and in Japan suggests that narrow money ratios can affect the level of the nominal exchange rates, and the level of nominal exchange rates can affect the level of real activity.

${ }^{10}$ Japan does not have a ready series of consumer inflationary expectations. Of the various surveys, the Consumer Confidence Survey collected by Bank of Japan, which begain in 1971, covers the longest period. This survey is thus useful in conducting time-series analysis. A major limitation is that its information is qualitative, that is households are asked if future price changes are expected to be "lower" or "higher." Following Ueda (2009), we transform this information into quantitative information by using the method of Carlson and Parkin (1975). We thank Professor Kozo Ueda of Waseda University and formerly from the Bank of Japan to give us his EXCEL programs for converting the qualitative information in the Consumer Confidence Survey to quantitative information on inflation rates.

${ }^{11}$ The output gap is defined as: $\frac{y_{t}-y_{t}^{*}}{y_{t}^{*}}$,where $\mathrm{y}^{*}$ is potential output. A positive output gap means that current output is above potential output. Potential output is calculated as the trend output level from a Hodrick-Prescott filter.
} 
in addition include as exogenous variables, U.S. macroeconomic variables such as the U.S. output gap, the U.S. CPI inflation rate, and U.S. log base money. In most cases, including the U.S. macroeconomic variables as exogenous conditioning variables did not make a difference in the pattern of impulse responses. The monetary policy shocks-defined to be the unexplained fluctuations in nominal interest rates and in base money-are small, given that the VARs of the kind that we estimate have R-squared of above 0.95 for most of the equations (Boivin and Giannoni, 2002).

In all vector regressions, the optimal lag length was chosen to be two or three quarters by the Swartz criterion. In all cases, the roots of the vector regressions were shown to be within the unit circle, implying the stability of the regressions.

\subsubsection{Impulse Responses.}

Our first set of impulse responses (Figure 7) are based on the subset of variables: $\left\{\mathrm{y}_{g}^{J}, \pi^{J}, i^{J}, \pi^{e}\right\}$.Since our interest is mostly in the impact of Japanese monetary policy variables on other macroeconomic variables, we focus on the impact of a shock to $\mathrm{i}^{J}$ on $\mathrm{y}_{g}^{J}$ and $\pi^{J}$ and $\pi^{e}$. We examine the generalized impulse responses of Pesaran and Shin (1999), since these responses are immune to the ordering of the variables in the vector autoregression.

The results generally accord with most accepted macroeconomic models. A positive interest rate shock initially raises the output gap, but soon, the output gap turns negative, as recession gradually sets in with tighter money. Actual inflation rates decline with an increase in interest rates.

An increase in short term interest rates initially lowers inflationary expectations, but then inflationary expectations rise, suggesting that agents may be inferring from the rise in interest rates, that monetary authorities expect future inflation rates to be high.

Our findings show that a tightening of Japanese interest rates results in a fall in actual inflation, while the link from tightening interest rates to a rise in inflationary expectations is more ambiguous. Our results are robust to different starting samples and also to the inclusion of exogenous U.S. macroeconomic variables.

We next depict impulse responses (Figure 8) when log base money is added to the initial set of variables: $\left\{\mathrm{y}_{g}^{J}, \pi^{J}, i^{J}, \pi^{e}, m^{J}\right\} .{ }^{12}$ We focus on the impact of shocks to the monetary variables, $i^{J}, m^{J}$. The inclusion of $\log$ base money leaves unaffected, the effect of a positive interest rate shock on the output gap

\footnotetext{
12 Conference participants have pointed out that the one year ex ante real interest rate should be included as a monetary policy measure instead of broad money. In the VAR specification above, ex ante real interest rates are implicitly included, through the inclusion of inflationary expectations and the (three month) nominal interest rate.

Also, as Figure 6 shows, Japanese inflationary expectations are sluggish, so real interest declines since early 2013 have been small. The scale of monetary expansion since early 2013 can be better captured by the depreciation of the nominal exchange rate and the expansion in base money.
} 
(positive) and actual inflation (negative). Now on impact, a positive shock to interest rates lowers inflationary expectations, which is what we expect.

Although the effects are small, a positive shock to base money lowers the output gap on impact, but then the output gap starts to rise over time. After a positive shock to base money, the inflation rate immediately rises, and then falls, while the shock induced increase in inflationary expectations is small. Gradually, the output gap tends to rise, suggesting that expanding money supplies takes time to work.

These impulse responses to a positive shock to base money are sensitive to the inclusion of the post-2000 sample. When the post-2000 sample is dropped from the vector autoregression estimates (not depicted), a positive shock to base money sharply raises the the output gap on impact, but then the output gap slowly starts to decline. The inflation rate immediately rises, and then falls. In sum, regardless of the sample for which the vector autoregressions are estimated. a shock to base money raises the output gap, either immediately (excluding the post-2000 sample) or eventually, and immediately raises the actual inflation rate in all samples.

Our third set of impulse responses (Figure 9) depict the results including the nominal yen-dollar exchange rate into the vector autoregressions: $\left\{\mathrm{y}_{g}^{J}, \pi^{J}, i^{J}, \pi^{e}, m^{J}, e\right\} . \mathrm{A}$ shock to interest rates has the same effects on $\mathrm{y}_{g}^{J}, \pi^{J}, i^{J}, \pi^{e}$ as before. As in many earlier findings in the literature (Kim and Roubini, 1999), a positive shock to interest rates has a tendency to depreciate the Japanese exchange rate, because of the failure of uncovered interest rate parity (not depicted). Importantly, when the yen-dollar exchange rate is included in the VAR system, a rise in Japanese short term interest rates lowers the output gap. As before, a positive shock to base money raises output, but with a lag, and raises the inflation rate over the medium term. A positive shock to base money depreciates the yen-dollar exchange rate (not depicted).

Finally, a shock to the nominal yen-dollar rate sharply raises the output gap on impact, and raises the actual and expected inflation rates. These expansionary effects of the depreciation of the nominal exchange rate accord with most conventional models. These results are robust to the estimation over various sample periods.

To summarize, we have shown that a positive shock to Japanese interest rates lowers the Japanese output gap, actual inflation rates, but over time tends to raise inflationary expectations and depreciate the nominal yen-dollar rate. A shock to Japanese base money lowers the output gap initially, but over time the output gap rises. Expansionary base money policies thus appear to take a while to work. The impact of a positive base money shock on inflation and inflationary expectations are positive in the short- to medium-runs. A shock to base money depreciates the yen-dollar rate. Finally, a yen-dollar rate depreciation raises the Japanese output gap and actual inflation and inflation forecasts.

\subsection{Effect of Monetary Variables on the Stock Market,}




\section{and Long term Interest Rates in Japan.}

In addition to depreciating the nominal exchange rate, the expansion of base money can expand the economy by raising stock market prices and lowering long term interest rates. One key result and perhaps even intent of the recent expansion of base money in Japan is the simultaneous rise in the Japanese stock market. In addition, the expansion of base money is also targeted to help reduce long-term interest rates, but here the evidence is less clear, as long-term interests rates have not decreased since the post-2012 base money expansion.

Below, we examine impulse responses from vector autoregressions that include in addition, the stock market values and the long term interest rates in Japan. The long term interest rate in Japan is the 10-year government bond interest rate, the value of the stock market is the log of the TOPIX index. We also include time dummies to capture the effects of changing monetary regimes. We include time dummies for the 1980s, 1990s, 2000-2008, and 2009 onwards and the Japanese CPI on food and energy as exogenous regressors, that is, $\left\{\mathrm{y}_{g}^{J}, \pi^{J}, i^{J}, \pi^{e}, m^{J}, e, s^{J}, i l^{J}\right\}$, where $s^{J}$ is the value of the Japanese stock market, and $i l^{J}$ is the Japanese long-term interest rate.

Figures 10 and 11 depict the results. The Figures show that both a cut in short term interest rates or an expansion in base money supply raises stock market values on impact, with the rise in base money having longer lasting effects on equity prices. Stimulative monetary policy in the form of a cut in short term interest rates sharply lowers long term interest rates, but a rise in base money supply actually raises long term interest rates. This latter result is perhaps because a rise in base money raises inflationary expectations, leading to a rise in long term interest rates.

Figure 11 shows that the output gap increases when there is an increase in stock market values and, surprisingly, a rise in long-term interest rates. A rise in stock market values appear to raise actual inflation rates in the short-run and expected inflation rates over a longer period. Inflation rates and inflationary expectations both appear to increase with shocks to long term interest rates.

Thus, it appears that in Japan, expansionary monetary policies that attempt to lower long-term interest rates have perverse effects on output, but monetary policies that raise stock market values appear to reliably raise Japanese output. Japanese long term interest rates are strongly influenced by actual and especially, expected inflation rates in the country. Thus, expansionary monetary policies that raise inflationary expectations tend to raise long term interest rates and output at the same time.

\section{Impact of Japanese Monetary Policy Variables on the U.S. Economy.}

As argued in Section 2, the expansion of Japanese monetary policy is likely to result in a better outcome for both Japan and the U.S. in the real world if 
the increase in Japanese output results in an increase in U.S. output, and the depreciation of the yen results in a smaller decline in U.S. output. Here we present vector autoregressions including both Japanese and U.S. variables. We examine the variables $\left\{\mathrm{y}_{g}^{u s}, \pi^{u s}, m^{u s}, i^{u s}, e, \mathrm{y}_{g}^{J}, m^{J}, \pi^{J}, i^{J}\right\}$, where the variables superscripted with "us" are U.S. variables. ${ }^{13}$ While we focus on the impact of Japanese monetary variables (the nominal short-term interest rate and base money) and the yen-dollar nominal exchange rate on the U.S. economy, we will also examine the impact of U.S. monetary variables on the Japanese economy.

For the entire sample, 1971 to 2013, Figure 12 depicts the impulse responses of one standard deviation shocks to the Yen-Dollar rate and short-term Japanese interest rate on the U.S. output gap. A depreciation of the yen has a slight but negative effect on the U.S. output gap over the short run. A fall in Japanese short-term interest rates slightly increases the U.S. output gap over the mediumrun, suggesting that overall, a loosening of Japanese interest rates has been stimulative towards the U.S. economy. On the other hand, a reduction in U.S. interest rates has a sharply negative effect on the Japanese output gap.

Figure 13 depicts the impulse responses of a shock to Japanese base money on the U.S. output gap, for the entire period, 1971 to 2013. An increase in Japanese base money sharply lowers U.S. output in the short-run, but the U.S. output gap starts to rise in about 8 to 9 quarters. The Japanese output gap also declines (very) sharply in response to a rise in U.S. base money until about 8 to 9 quarters. Note that an expansion in U.S. base money hugely appreciates the yen-dollar rate, implying that the decline in Japanese output is related to the appreciation of the yen.

Why does a cut in Japanese interest rates expand U.S. output, while an increase in Japanese base money lowers U.S. output in the short run? After all, according to most conventional open economy macroeconomic models, both are expansionary monetary policies and such policies should expand domestic output, while hurting foreign output in at least the short-run.

The reason is that while an increase in base money reliably depreciates the nominal exchange rate, a cut in short-term interest rates has an ambiguous effect on the nominal exchange rate (owing to the failure of uncovered interest rate parity). If an expansion in base money depreciates the nominal exchange rate, then domestic output would expand and foreign output should contract, at least in the short run.

For the sample, 1971 to 1999, a period that mostly excludes the two Japanese quantitative easing regimes after 2000, Figure 14 depicts the impulse responses of the output gaps to the Yen-Dollar exchange rate and the short-term interest rates. Compared to the sample that includes the post-2000 period, here the negative response of the U.S. output gap to the yen depreciation is much larger; a similar depreciation of the yen lowers the U.S. output gap by 3 times as much. ${ }^{14}$

\footnotetext{
${ }^{13}$ As an exogenous variable, we add the Japanese food and energy CPI index. We drop Japanese inflationary expectations from the VARs, since adding these expectations did not change any of our results.

${ }^{14}$ Perhaps this is because Japan's weight in the world economy has been declining; while
} 
In about 9 quarters, however, the impact of the depreciation of the yen on the U.S. output gap is back to zero. A decline in Japanese short-term interest rates increases the U.S. output gap from the short run; again a loosening of Japanese interest rates has been stimulative. As before, from about 1 to 8 quarters, a reduction in U.S. interest rates has had a sharply negative effect on the Japanese output gap.

Figure 15 depicts the impulse responses of a shock to Japanese base money on the U.S. output gap, from 1971 to 1999. An increase in Japanese base money lowers U.S. output for about 6 quarters. After an initial positive effect, in about 3 quarters, a rise in U.S. base money also sharply lowers the Japanese output gap. Again, an expansion in U.S. base money strongly appreciates the yen-dollar rate over about 9 quarters.

For the sample 1995 to 2013, Figure 16 depicts the impulse responses of one standard deviation shocks to the Yen-Dollar rate and short-term interest rates on the U.S. and Japanese output gaps. Given the shorter sample size and the fact that this period was characterized by massive doses of quantitative easing in both Japan and the U.S., we should expect these results to be different from earlier, but more relevant than the earlier results in examining the international spillovers from changes in monetary policy. Indeed, the response of U.S. output to a depreciation of the yen is quite different from before; now a depreciation of the yen raises the U.S. output gap for about 9 quarters.

As before, a cut in Japanese short-term interest rates is stimulative, increasing U.S. output after about 4 quarters. However, unlike before, a cut in U.S. short rates is also highly stimulative for Japan (for 9 quarters). Since short-term interest rates in Japan and in the U.S. were close to zero for much of the period after 2000, perhaps it is not surprising to find the effects of interest rate shocks on output gaps to be sharply different from the earlier periods.

Figure 17 depicts the impulse responses of shocks to base monies on U.S. and Japanese outputs from 1995 to 2013. Unlike during the earlier period, U.S. output now responds positively to an expansion in Japanese base money. In response to an expansion in U.S. base money, Japanese output declines as before for about 5 quarters, before increasing. As earlier, the yen-dollar rate sharply depreciates (appreciates) in response to an increase in Japanese (U.S.) base, suggesting that the Soros effect (the depreciation of the yen-dollar rate to an increase in the ratio of Japanese to U.S. base money) holds particularly firmly during 1995 to 2013.

We next focus on the effects of output gap shocks. Figure 18 depicts the impulse responses of shocks to the U.S. output gap on the Japanese output gap; and the Japanese output gap on the U.S. output gap (using the same VAR specification as above, for the period 1971-2013). A positive shock to the Japanese output gap has a positive effect on the U.S. output gap, and vice versa. This also holds for the sample periods 1971-1999 and 1995-2013 (not depicted). In general, a one standard deviation shock to the U.S. output gap has about

before 2000, Japan's weight in the global economy was as much as 20 percent; recently it has been below 10 percent, owing to the rapid growth in the emerging economies. 
as twice an effect on the Japanese output gap as does an identical shock to the Japanese output gap on the U.S. output gap. This is because U.S. output is over twice that of Japanese output. Shocks to output gaps can be interpreted as shocks to excess demand. ${ }^{15}$ Thus, a monetary fueled expansion in the Japanese output gap will raise the U.S. output gap through increased Japanese demand.

Taken as a whole, the results here suggest that at least in the short-run, an expansion in the base money of one country will have negative spillovers on the other country, owing to the depreciation of the nominal exchange rate, although past about 9 quarters (2 years), the negative effects become zero as positive spillovers effects from the domestic GDP expansion on the partner country take root.

The positive spillovers occur, because the increase in base money expands domestic output (through a domestic exchange rate depreciation or rise in asset prices), and the domestic output expansion raises foreign output. Thus, in the context of the model in Section 2, looser monetary policies in one country appear to have both negative (in the short-run) and positive (in the medium to long-run) spillovers on the other country. Interestingly, for the sample after 1995, a base money expansion by Japan has an unequivocal positive effect on U.S. GDP, both in the short- and in the medium-runs.

\subsubsection{Spillover Effects of Abenomics Monetary Policies on the U.S. Economy}

Since taking office in 2013, Prime Minister Abe has embarked on a massive loosening of base money, in an attempt to stimulate the Japanese economy. According to Hoshi (2014), between the end of 2012 and the end of 2014, the Bank of Japan plans to increase the monetary base to 270 trillion yen, which is 132 trillion yen larger than the monetary base at the end of 2012. This represents a 96 percent increase in the monetary base in the two years since 2012. Here we will use the elasticities calculated from our impulse responses above, to examine the effects of this Japanese base money loosening on the U.S. output gap. As mentioned, owing to this Japanese monetary expansion, there is likely to be negative U.S. GDP spillovers from the yen depreciation and positive U.S. GDP spillovers from the Japanese GDP increase. We can then calculate the net effect on the U.S. output gap of these two offsetting spillovers.

We compute for each period, the change in the U.S. output gap arising from the yen depreciation by multiplying the elasticity of the change in the U.S. output gap with respect to a change in yen-dollar rate by the percentage depreciation in the yen-dollar rate. These cumulative elasticities can be computed from the impulse responses above. Using the VARs estimated from the sample 1971 to 2013, the cumulative elasticities are 0.00 upon impact, 0.00 after 3 quarters, -0.01 after 6 quarters, and -0.02 after 9 quarters.

\footnotetext{
${ }^{15}$ Positive output gap shocks can also be interpreted as fiscal expansions or positive productivity shocks. Thus, a tax cut or government spending increase in Japan will increase U.S. output.
} 
From the end of 2012 to May 2014, the yen-dollar rate went from 87 to 102, an 18 percent depreciation. In our VARs, we are not explicit about how much of this depreciation in the yen has been anticipated prior to the end of 2012 . Here we simply assume that the entire 18 percent depreciation in the yen was an unanticipated shock.

From our quarterly time series data on the yen (from 1995 to 2013), we know that the standard deviation of the yen-dollar rate is about 15 , or about 14 percent of the average yen-dollar rate during this period. Thus, the yen-dollar rate depreciation since the end of 2012 to now represents about a 1.25 standard deviation depreciation.

Multiplying the cumulative elasticities above by the 1.25 standard deviation shock to the yen-dollar exchange rate, we find that the depreciation of the yen should have reduced the U.S. output gap by about 1.25 percent after 6 quarters.

We can then compute for each period, the change in the U.S. output gap arising from the Japanese output gap shock by multiplying the elasticity of the change in the U.S. output gap with respect to a change in the Japanese output gap. Using the VARs above, the cumulative elasticities are 0.0 upon impact, 0.01 after 3 quarters, 0.02 after 6 quarters, and 0.025 after 9 quarters. The actual increase in the Japanese output gap is about 1 standard deviation from the end of 2012 to the present. Multiplying the cumulative elasticities by the 1 standard deviation shock to the Japanese output gap, we find that the increase in the Japanese output gap should have increased the U.S. output gap by 1 percent, 2 percent, and 2.5 percent in 3,6 , and 9 quarters respectively.

Given these responses of the U.S. output gap to the yen depreciation and Japanese output gap increase, we calculate that the positive impact on the U.S. output gap of a rise in the Japanese output gap is larger than the negative impact on the U.S. output gap of a depreciating yen-dollar exchange rate (2 percent increase versus a 1.25 percent decrease after 6 quarters). Thus, on net, the expansion in Japanese base money has had positive spillovers on U.S. GDP.

\subsection{Multicounty Vector Autoregressions.}

Using VARs, we have so far examined whether expansionary monetary policies in Japan have resulted in increases in the output gaps and inflation rates in Japan and in the U.S. Although yen-dollar policies are largely determined in discussions between the Ministry of Finance in Japan and the Treasury Department in the U.S., movements in the yen-dollar nominal exchange rate usually affect the domestic economies of Japan's other trading partners as well.

For example, the nominal yen-dollar rate, the nominal won-yen rate, Japan's nominal effective and real effective exchange rates tend to be very highly correlated. The correlation coefficients between the nominal yen-dollar rate, the nominal won-yen rate, and the Japanese nominal and real effective exchange rates are $0.92,0.91$, and 0.58 respectively, in monthly data from 1980 to mid2013. These high correlations suggest that a change in the nominal yen-dollar 
is highly correlated with changes in Japan's exchange rate with other important trading partners. In the case of Korea, a depreciation of the yen against the dollar will tend to appreciate the won against the yen, thereby hurting the competitiveness of Korean tradeable industries. Thus, we should examine the spillover effects of Japanese monetary policies not only on the U.S., but also on other Japanese trading partners.

Here we adopt the GVAR model of di Mauro and Pesaran (2013) to examine how shocks to Japanese monetary policies are transmitted, not only to the U.S., but also to other Japanese trading partners. The GVAR model is essentially a multicountry vector autoregression model with enough exogeneity assumptions to make the model estimable and to conduct impulse responses. There are currently 33 countries in the GVAR model. The rest of Asia bloc includes nonJapan, non-China countries such as Korea and the Southeast Asian nations.

The variables included in our particular version of the GVAR model are the nominal short-term interest rate, the nominal long-term interest rate, the inflation rate, real equity prices, the real exchange rate $^{16}$, and real GDP. Since we are primarily interested in the impact of expansionary monetary policies, we first examine shocks to the nominal short-term interest rates. ${ }^{17}$

In the GVAR model, declines in U.S. short-term nominal interest rates have large positive international spillover effects on the GDP of all countries (not depicted). A one standard error negative shock to U.S. nominal short-rates raises U.S. GDP, Japanese and rest of Asian GDPs after one period. The Japanese real exchange rate (against the U.S. dollar) appreciates for the entire period, while rest of Asian exchange rates (against the U.S. dollar) first appreciates, then depreciates. Equity prices appreciate in the U.S., Japan, and in the rest of Asia.

In the GVAR model, changes in Japanese short-term nominal interest rates have negative short-run effects on Japanese neighbors. A fall in Japanese short rates does not lower U.S. or rest of Asian short-term rates. Real GDPs in Japan, Asia, and the U.S. decline (not depicted). The yen and other Asian currencies depreciate against the U.S. dollar, while equity prices increase in Japan, the rest of Asia, and in the U.S. Long-term interest rates in Japan and in the rest of Asia fall.

As in the Japan-U.S. vector autoregressions, the decline in short-term interest rates do not directly positively impact output abroad (or even domestically in Japan), but may indirectly impact foreign output through the Japanese short-term interest rates' effect on Japanese long-term interest rates and equity prices.

A one standard error decline in Japanese long-term interest rates expands Japanese GDP, and the GDPs in other Asian countries, but slightly lowers the GDP of the U.S. A one standard error increase in Japanese equity prices unambiguously increases the GDPs of Japan, the rest of Asia and the U.S. (not

\footnotetext{
${ }^{16}$ The exchange rates are bilateral vis-a-vis the U.S.

${ }^{17}$ Since base money data are not available for a broad cross-section of countries, we could not include them in the VAR analysis.
} 
depicted). A depreciation of the real yen against the U.S. dollar raises Japanese GDP, but lowers the GDPs of Asia and the U.S (Figure 19). Finally, Figure 20 shows that the expansion of Japanese GDP ambiguously expands the GDPs of Asia and the U.S.

Thus, while expansionary Japanese monetary policies are likely to lower the GDPs of the U.S. and non-Japan Asia through the depreciation of the real yendollar rate, such policies should help expand the GDP of Japan through the decline in long term interest rates and the rise in the yen. Over the medium- to long-runs, the expansion of Japanese GDP, and equity and bond prices should help raise the GDPs of the rest of Asia and the U.S.

\section{Conclusion.}

In this paper, we showed theoretically in a two country classical model that an expansion in Japanese monetary policy need not be coordinated with an expansion of U.S. monetary policy for the two country model to result in a pareto-optimal outcome. We argued that if an expansionary monetary policy in Japan resulted in positive spillovers for the U.S., then U.S. may be less hurt by a Japanese monetary expansion induced exchange rate appreciation, and may actually benefit. While a monetary expansion induced currency depreciation in one country can hurt the output of the other country, if the monetary expansion causes an increase in GDP in the one country, say from an increase in equity prices, then both countries can benefit from the monetary expansion in the one country.

To test the broad implications of the theory, we examine several impulse responses from vector autoregressions. The single, two country, or multicountry vector autoregressions show that the expansion in Japanese monetary policy, whether due to a cut in short-term interest rates or an expansion in base money, always results in a depreciation of the yen. The depreciation of the yen or the rise in equity prices caused by the looser Japanese monetary policy always expands Japanese GDP.

We show in our impulse responses from our two- and multicountry VARs that while the depreciation of the yen will lower somewhat U.S. and Asian GDPs, the expansion in Japanese GDP always raises the GDPs of the U.S. and Asia. Thus, there is empirical justification that Japanese expansionary monetary policy, while depreciating the yen, can help expand the GDPs of the U.S. or its Asian neighbors, through the rise in Japanese GDP. 


\section{References}

[1] Arai, Y. and T. Hoshi, 2006, "Monetary Policy in the Great Recession," in Hutchison, M. and F. Westerman (eds.) Japan's Great Stagnation, Cambridge: MIT Press.

[2] Boivan, J. and M. Giannoni, 2002, "Assessing Changes in the Monetary Transmission Mechanism: A VAR Approach," FRBNY Economic Review, May 2002.

[3] Christiano, L., M. Eichenbaum, and R. Vigfusson, 2007, "Assessing Structural VARs," NBER Macroeconomics Annual, 2006, 21, pp. 1-106. Chicago: NBER.

[4] Chari, V., P. Kehoe, and E. McGrattan, 2008, "Are Structural VARs with Long-Run Restrictions Useful in Developing Business Cycle Theory," Journal of Monetary Economics, 55(8), pp. 1337-1352.

[5] Cooper, R., 1985, "Economic Interdependence and the Coordination of Economic Policies," in R. Jones and P. Kenen (eds.), Handbook in International Economics, 1985.

[6] Di Mauro and H. Pesaran, 2013, The GVAR Handbook, Oxford: Oxford University Press.

[7] Eichengreen, B. and J. Sachs, 1985, "Exchange Rates and Economic Recovery in the 1930s," Journal of Economic History,45, pp. 925-946.

[8] Eichengreen, B. and J. Sachs, 1986, "Competitive Devaluation and the Great Depression," Economics Letters, H22, pp. 67-71.

[9] Fernandez-Villaverde, Rubio-Ramirez, J., and T. Sargent, and M. Watson, 2008, "ABCs (and Ds) of Understanding VARs" American Economic Review, 97(3), pp. 1021-1026.

[10] Fujiwara, I., 2006, "Evaluating Monetary Policy When Nominal Interest Rates Are Zero," Journal of the Japanese and International Economies, 20(3): $434-453$.

[11] Hamada, K., 1985. The Political Economy of International Monetary Interdependence. Cambridge: MIT Press.

[12] Hamada, K., 1976, "A Strategic Analysis of Monetary Interdependence, " Journal of Political Economy, 677-700. 
[13] Hamada, K. and Y. Okada, 2009, "Monetary and International Factors Behind Japan's Lost Decade," Journal of the Japanese and International Economies, 200-219.

[14] Hausman, J.K. and J.F. Weiland, 2014, "Abenomics: Preliminary Analysis and Outlook," Brookings Papers on Economic Activity.

[15] Hayashi, F. and J. Koeda, 2013, "A Regime-Switching SVAR Analysis of Quantitative Easing," mimeographed, Tokyo University.

[16] Hoshi, T., 2014, "Can Abenomics Restore Japan's Growth?," Macroeconomy Proceedings, Nomura Foundation.

[17] Hutchison, M. and R. Ratum, 2004, "Foreign Exchange Intervention and Monetary Policy in Japan, 2003-2004," EPRU Working Paper.

[18] Inoue, T. and T. Okimoto, 2008, "Were there Structural Breaks in the Effects of Japanese Monetary Policy" Re-evaluating Policy Effects of the Lost Decade," Journal of the Japanese, and International Economies, 22, pp. $320-342$.

[19] Kim, S., 1999, "Do Monetary Policy Shocks Matter in the G-7 Countries: Using Common Identifying Assumptions About Monetary Policy Across Countries," Journal of International Economics, 48, 387-412.

[20] Kim, S. and N. Roubini, 2000, "Exchange Rate Anomalies in Industrial Countries: A Solution with a Structural VAR Approach," Journal of Monetary Economics,45, 561-586.

[21] Kimura, T. and J. Nakajima, 2013, "Identifying Conventional and Unconventional Monetary Policy Shocks: A Latent Threshold Approach," mimeographed, April.

[22] Korinek, A., 2013, "Capital Account Intervention and Currency Wars," manuscript, December.

[23] Michelis, A. and M. Iacoviello, 2014, "Raising an Inflation Target: the Japanese Experience with Abenomics," Federal Reserve Board.

[24] Nakajima, J. and T. Watanabe, 2011, "Bayesian Analysis of Time-Varying Parameter Vector Autoregressive Model with the Ordering of Variables for the Japanese Economy and Monetary Policy," mimeographed, Hitotsubashi University, July.

[25] Rogers, J. and J. Wright, 2014, "Evaluating Asst Market Effects of Unconventional Monetary Policy: A Cross-Country Comparison," Federal Reserve Board.

[26] Pesaran, H. and Y. Shin, 1998, "Generalized Impulse Response Analysis in Linear Multivariate Models," Economic Letters, 58, 17-29. 
[27] Sims, C., 1992, "Interpreting Macroeconomic Time Series Facts: The Effects of Monetary Policy," European Economic Review, (36)5: 975-1000.

[28] Sims, C. and T. Zha, 2006, "Does Monetary Policy Generate Recessions," Macroeconomic Dynamics,10, 231-272.

[29] Ueda, K., 2009, "Determinants of Household Inflation Expectations in Japan and in the U.S.," Journal of the Japanese and International Economies, (24)4: 503-518. 


\section{Figure 1(a)}

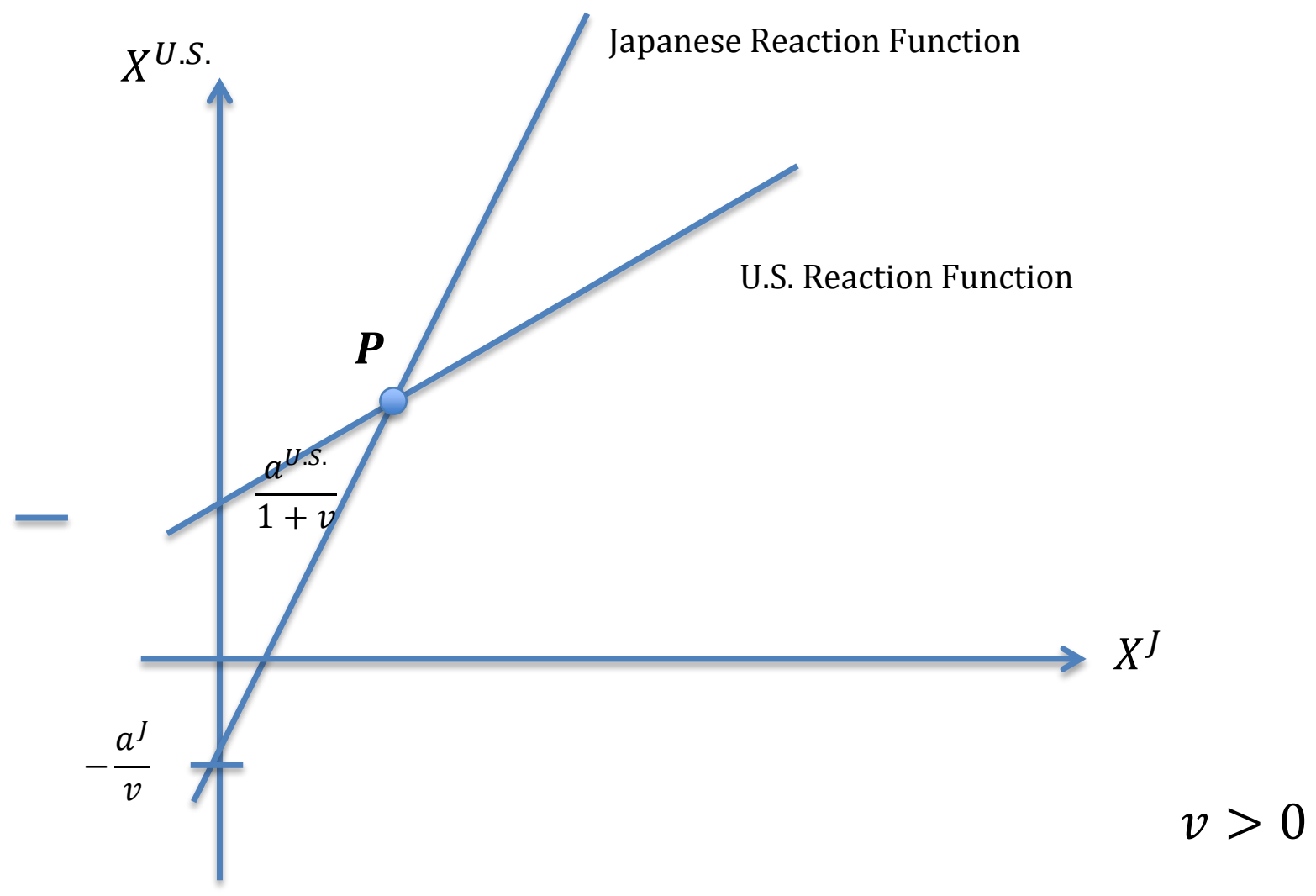

Figure 1(b)

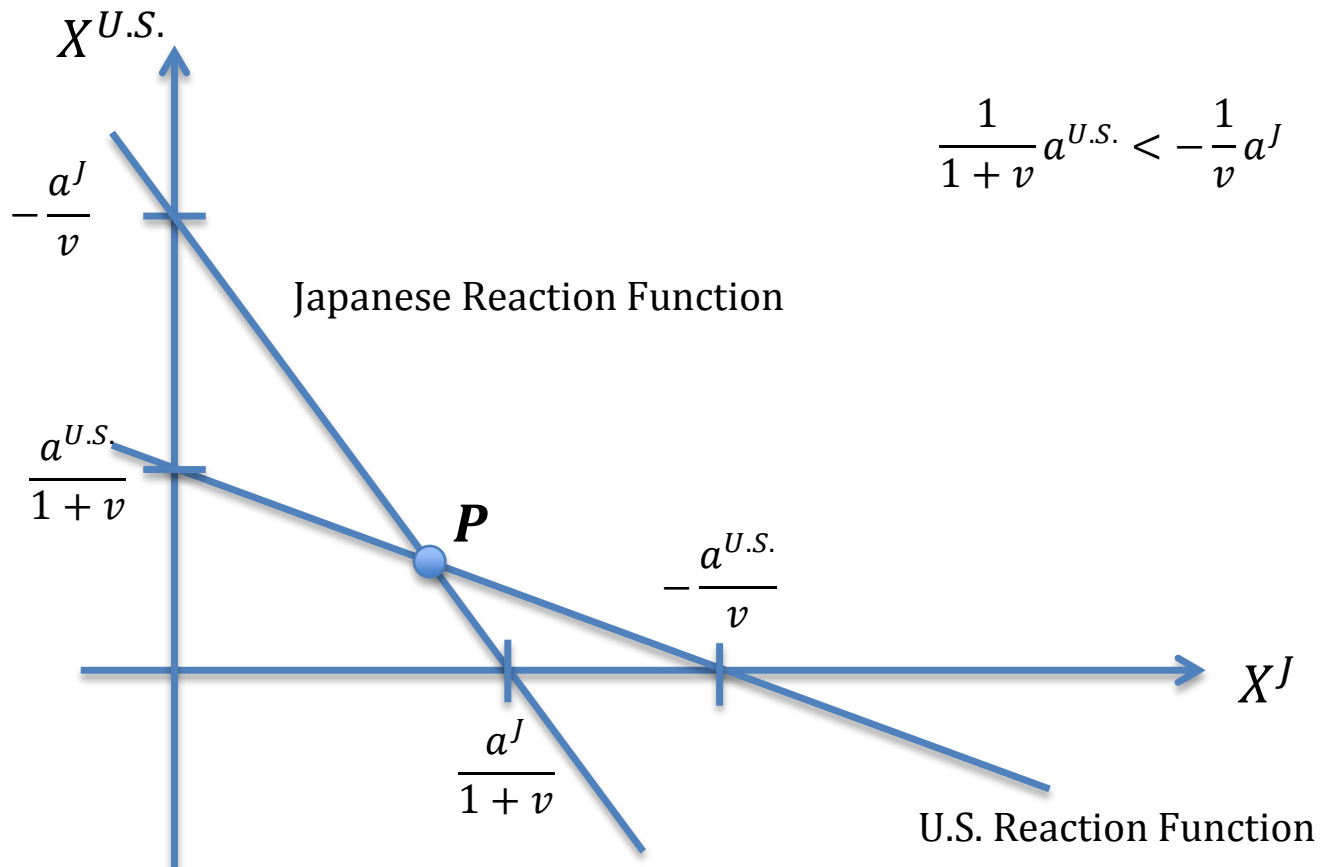


Figure 2: U.S. and Japanese Short-term Nominal Interest Rates (in percent)

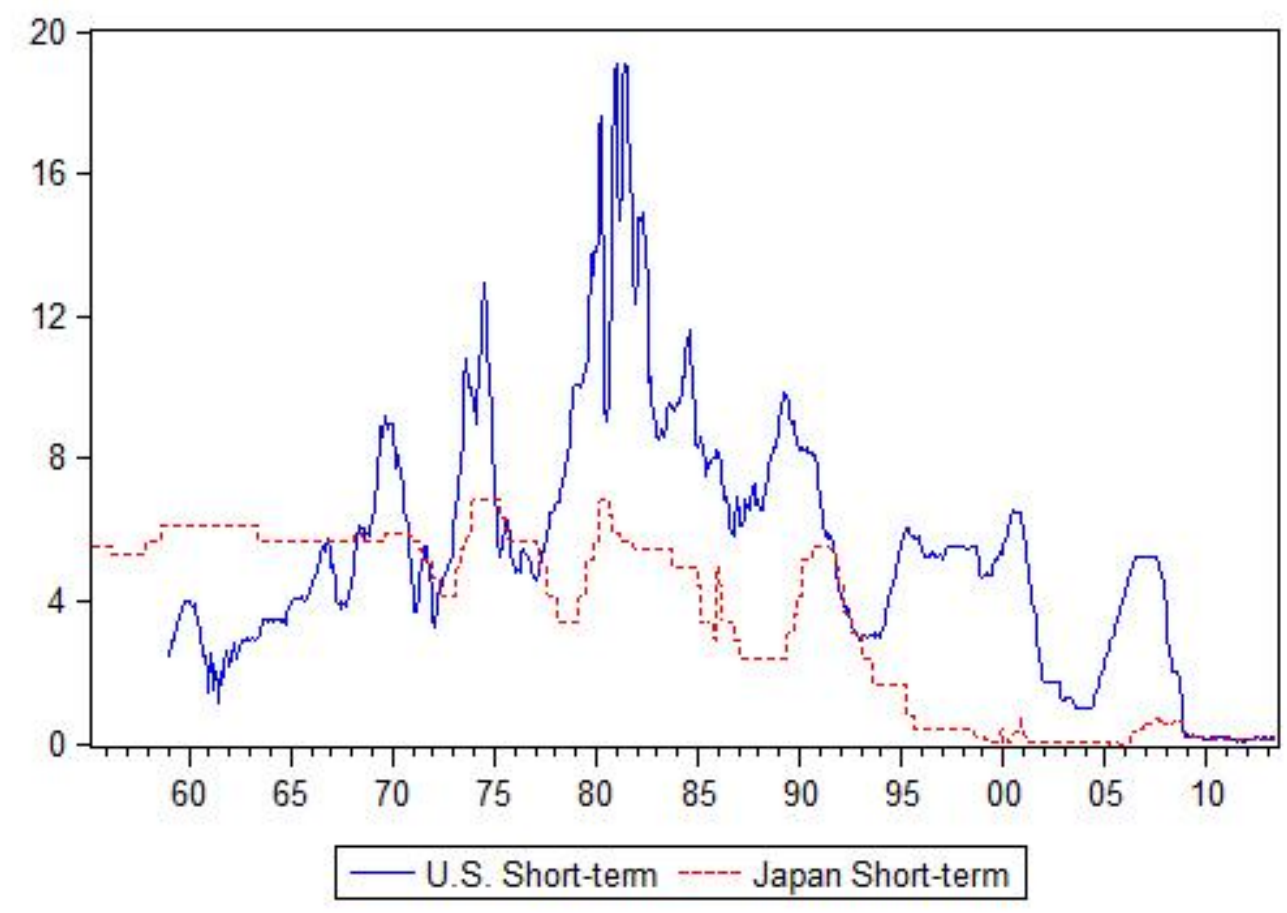


Figure 3: The Gap in U.S. and Japanese Short-term Interest Rates (DIFFINTER; in percent) and the Yen-Dollar Nominal Exchange Rate (EXJPUS)

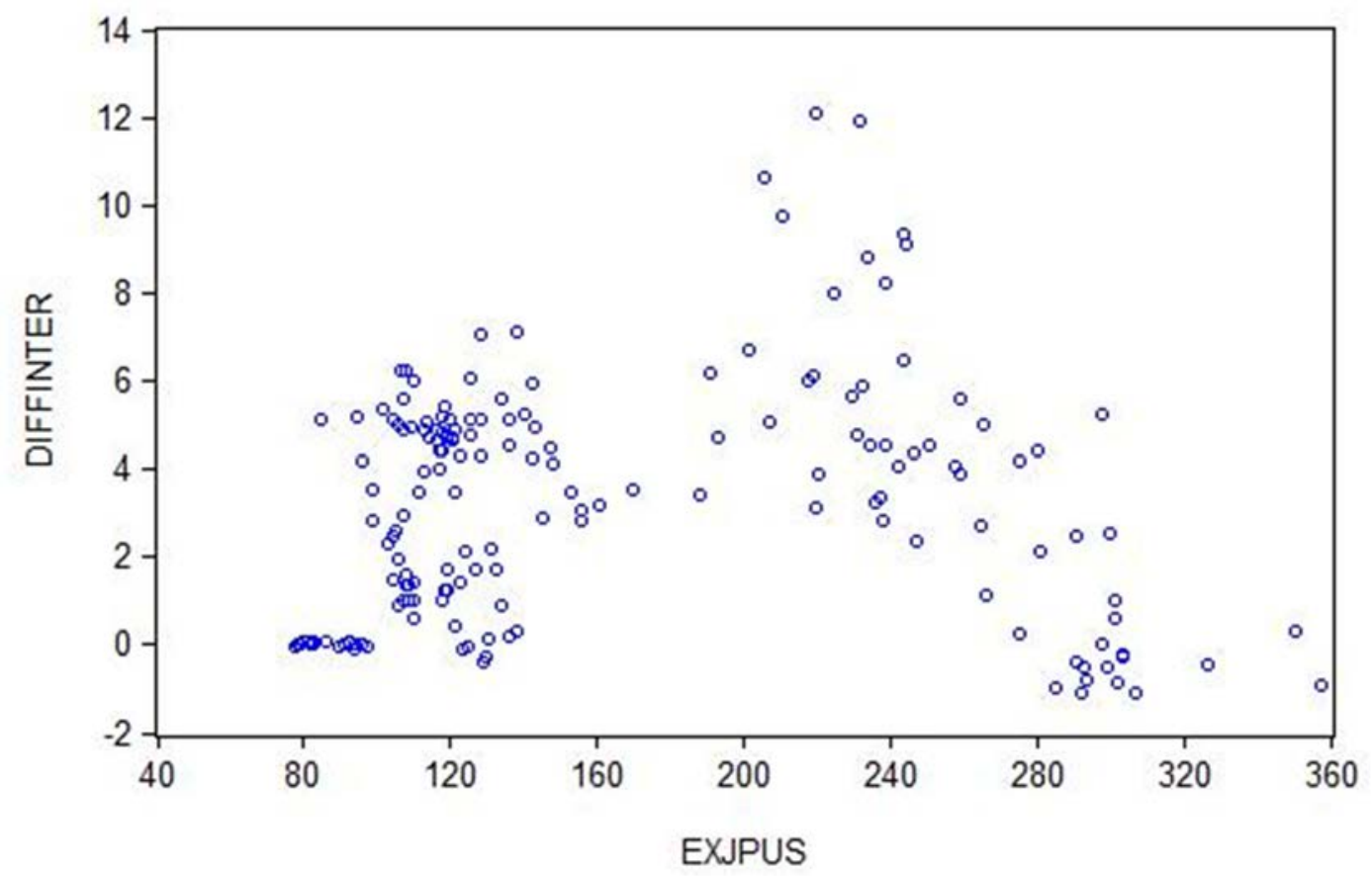


Figure 4: The Change in the Ratio of U.S. Base Money to Japanese Base Money

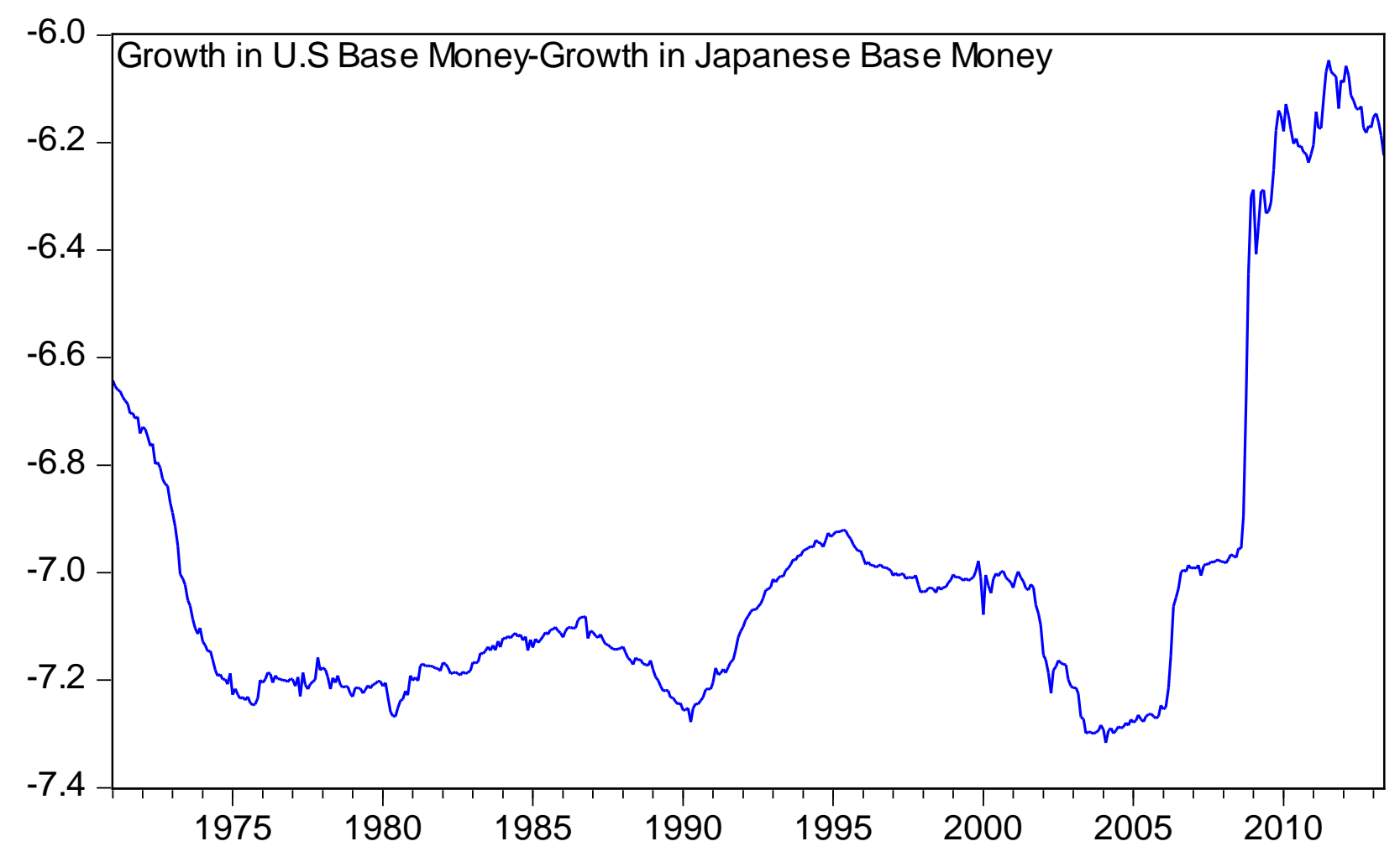


Figure 5: The Yen Appreciates when U.S. Base Money Grows Faster than Japanese Base Money

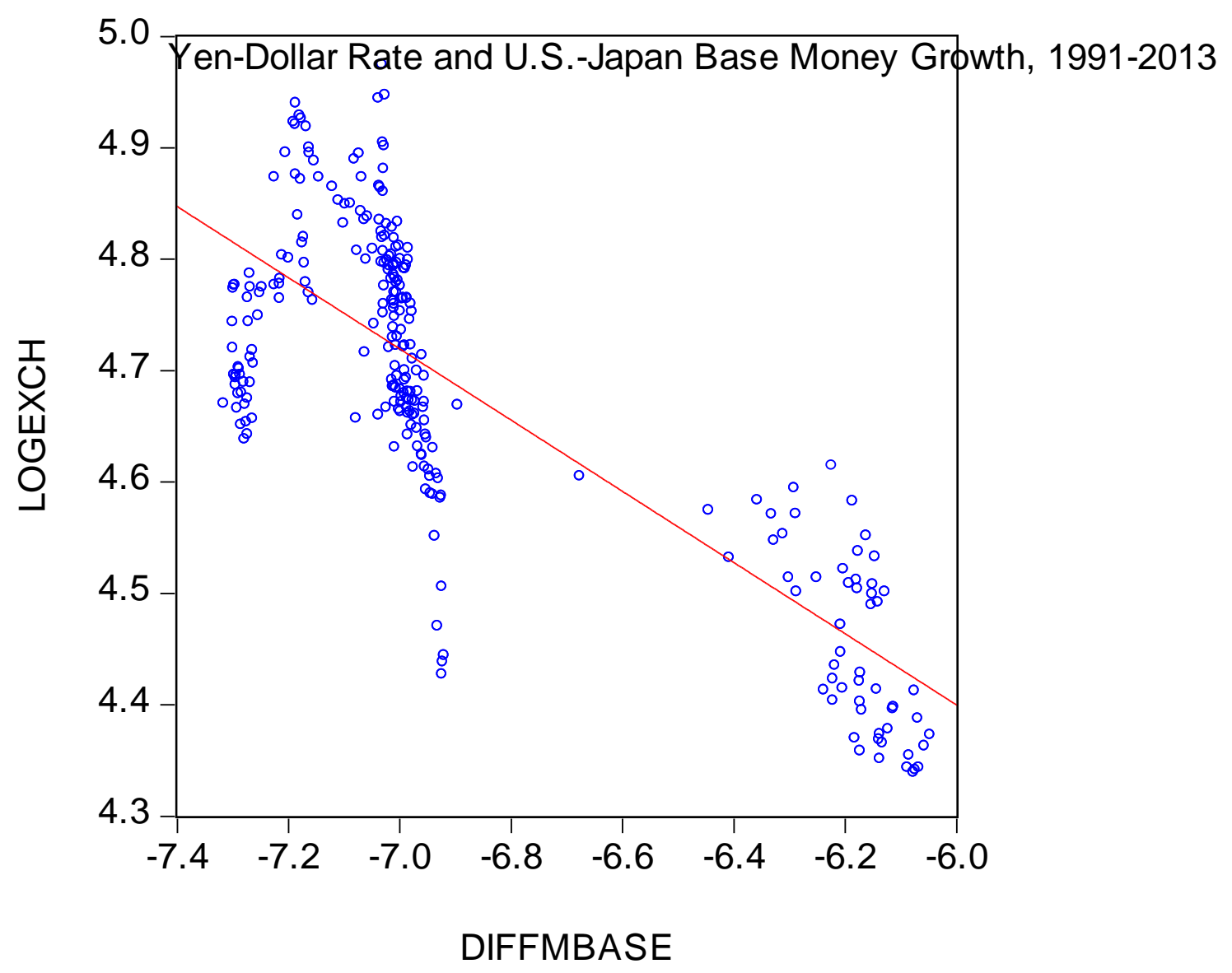


Figure 6: Japanese Actual CPI Inflation and One Year Ahead Household CPI Inflation Forecasts

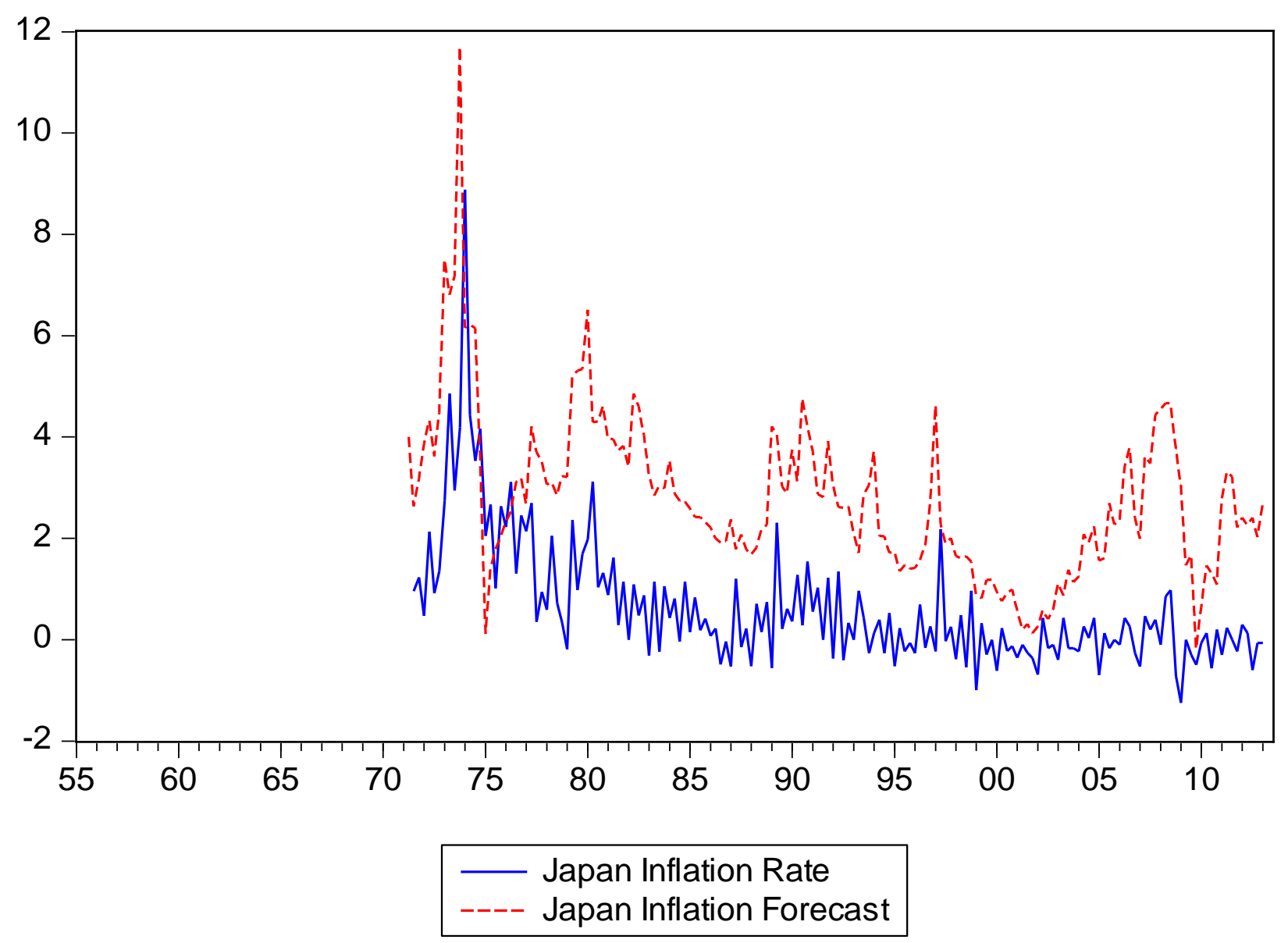


Figure 7: Japan: Impulse Responses of the Output Gap, Inflation, and Household Inflationary Forecasts to the Short-term Interest Rate Shocks

Response to Generalized One S.D. Innovations \pm 2 S.E. Output Gap to Short-term Interest

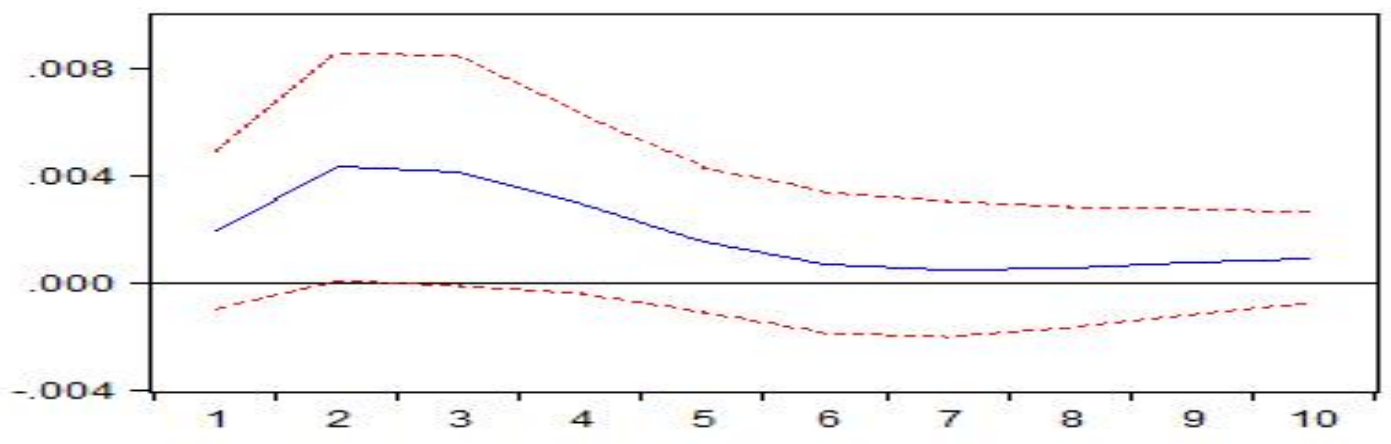

Inflation to Short-term Interest

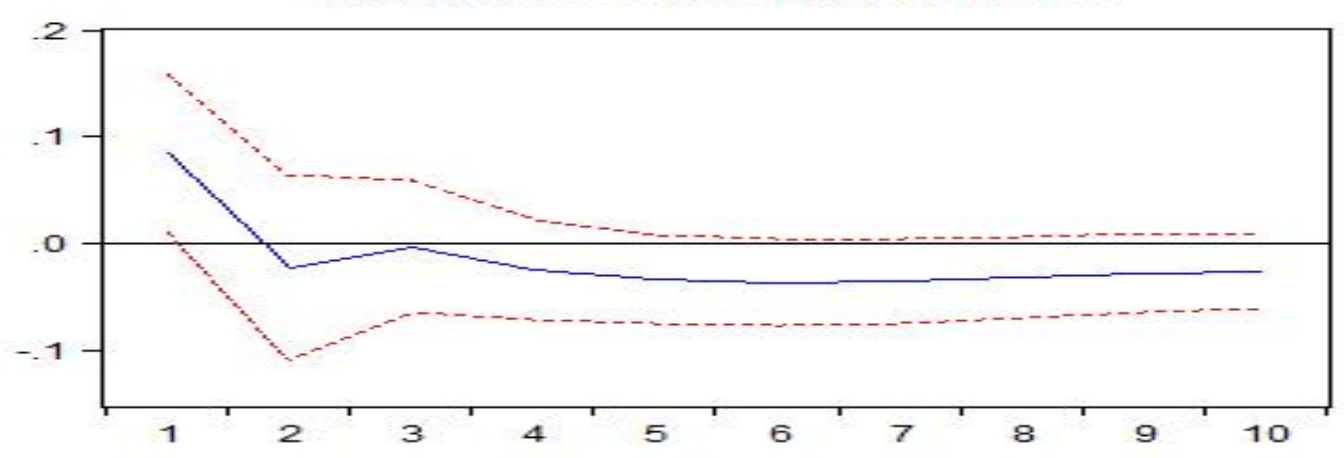

Inflation Forecast to Short term Interest

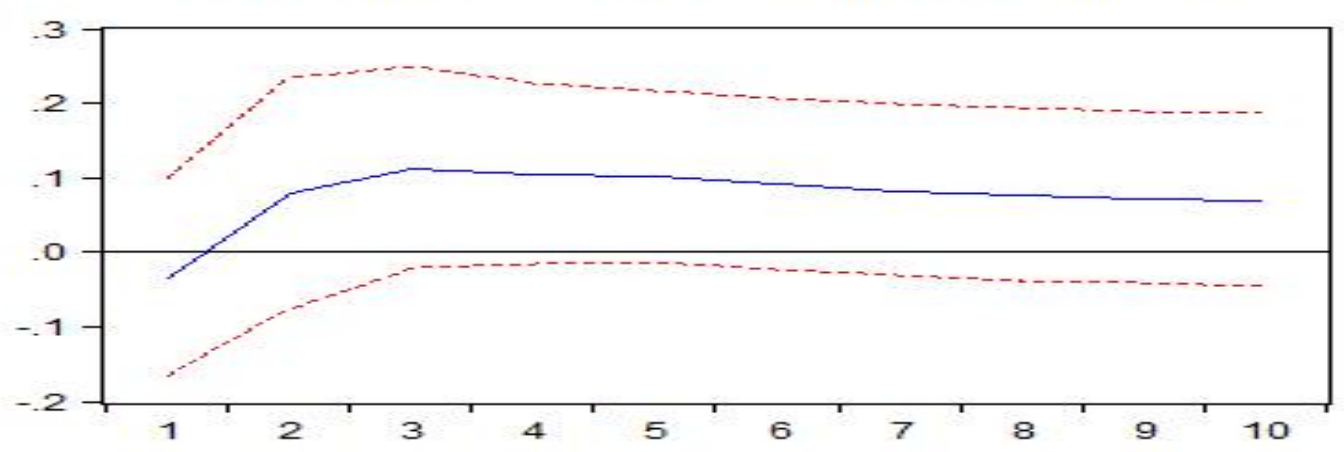


Figure 8: Japan: Impulse Responses of the Output Gap, Inflation, and Inflationary Forecasts to the Short-term Interest Rate and Base Money Shocks

Response to Generalized One S.D. Innovations \pm 2 S.E.
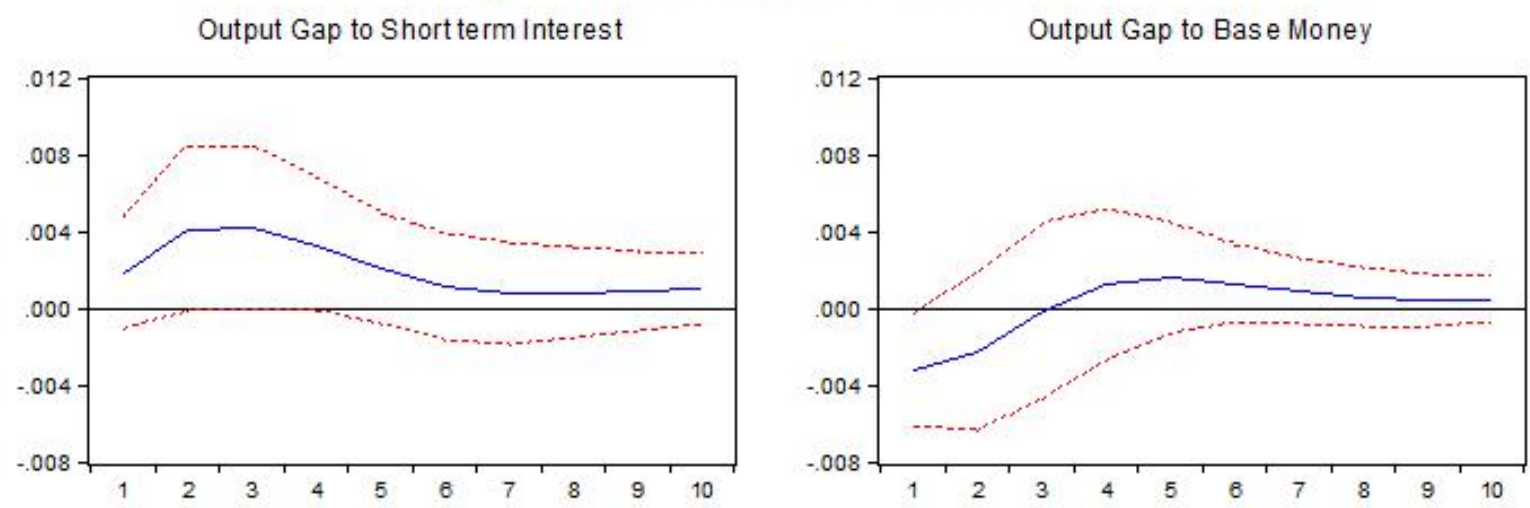

Inflation to Short term Interest

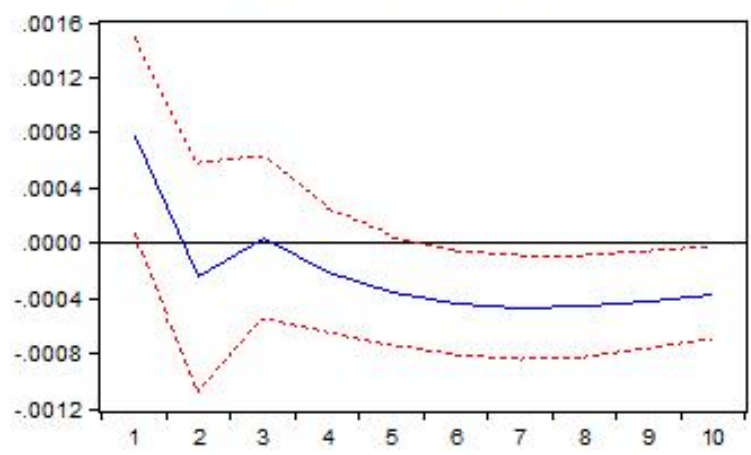

Inflation to Base Money

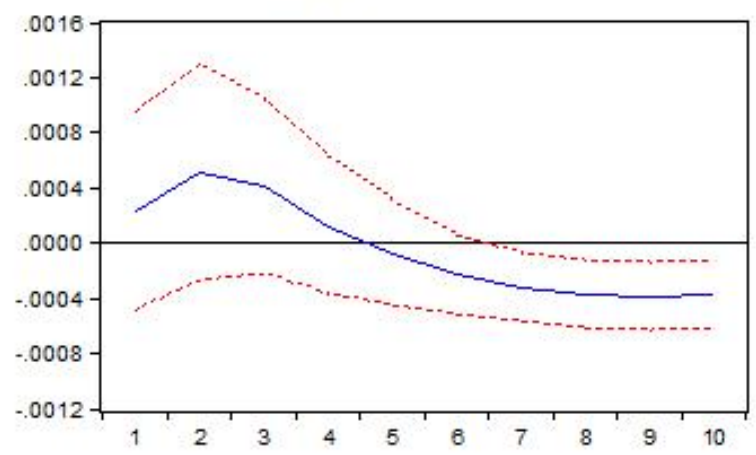

Inflation Forecast to Short term Interest

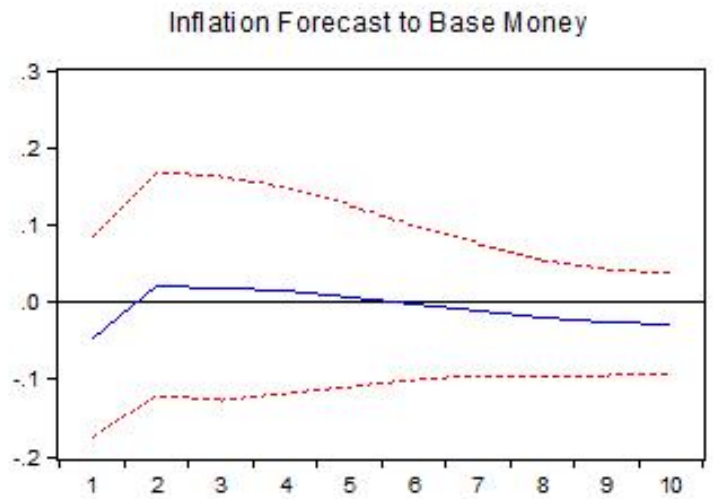


Figure 9: Japan: Impulse Responses of the Output Gap, Inflation, and Inflationary Forecasts to the Short-term Interest Rate, Base Money, and the Yen-Dollar Exchange Rate Shocks

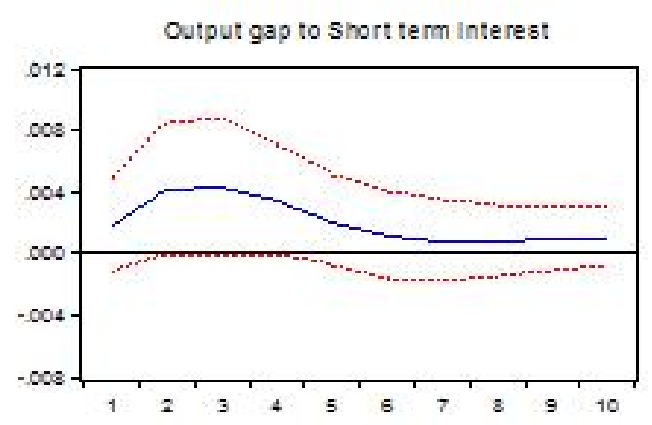

Response to Generalized One S.D. Innovations \pm 2 S.E.

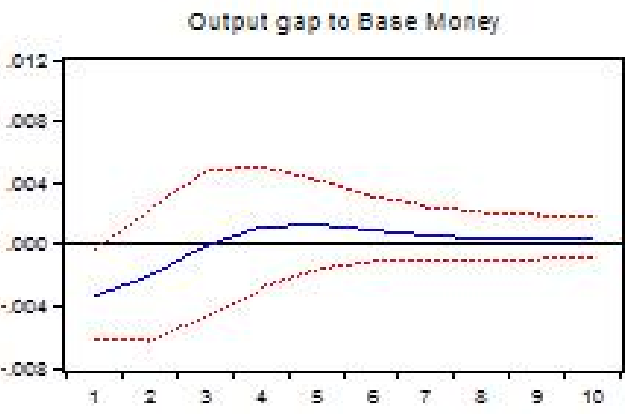

Outout gap to Yen-Dollar Exchange Rate

Output gap to Snort term interest

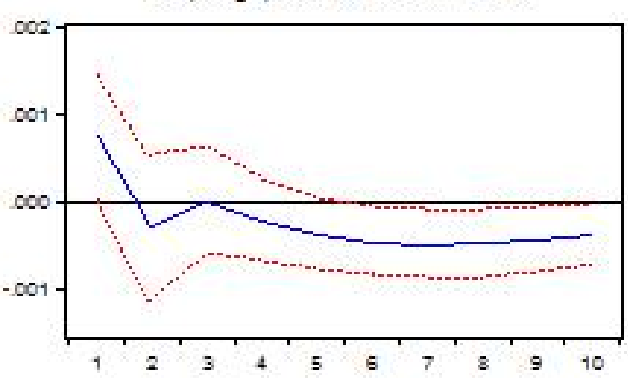

Inflation to Base Money

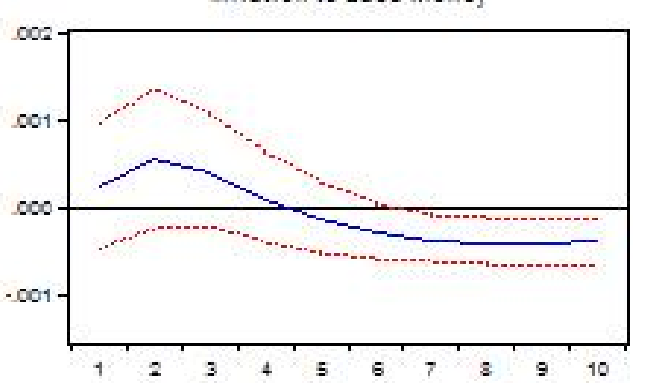

Inflation to Yen-Dollar Exchagne Rate

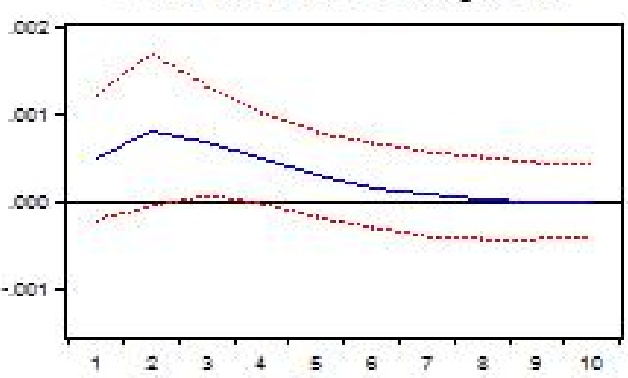

Inflation Forecast to Short term interest

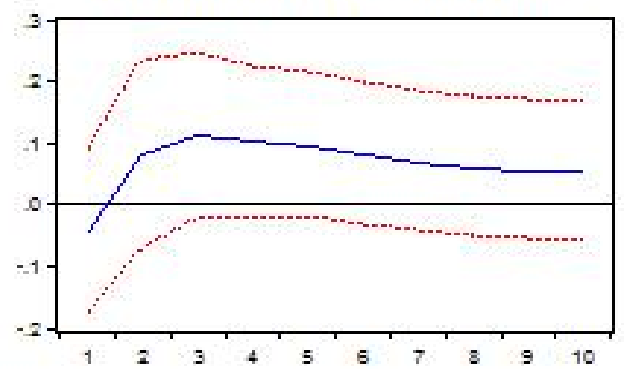

Inflation Forecast to Base Mone,

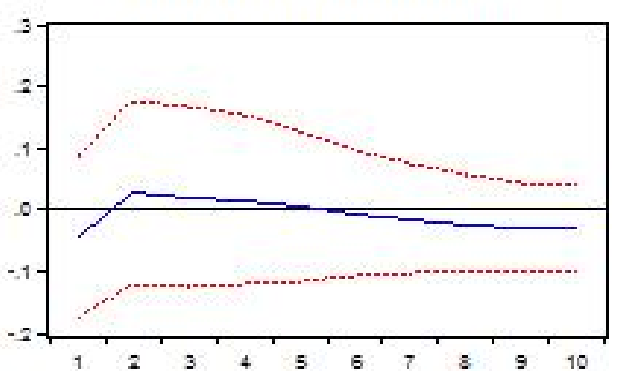

Iflation Forecase to Yen-Dollar Exchange Rate

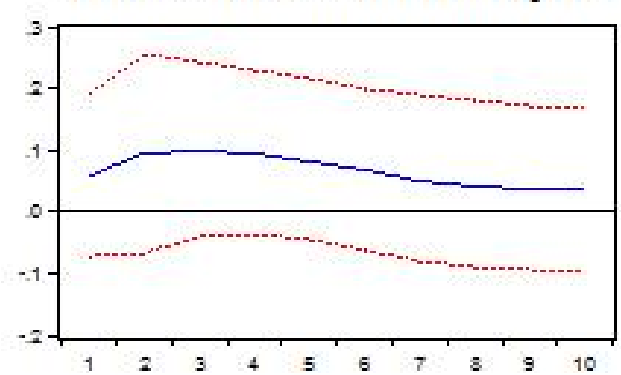


Figure 10: Japan: Impulse Responses of the Stock Market and Long-term Interest Rates to Short-term Interest Rate and Base Money Shocks

Response to Generalized One S.D. Innovations \pm 2 S.E.
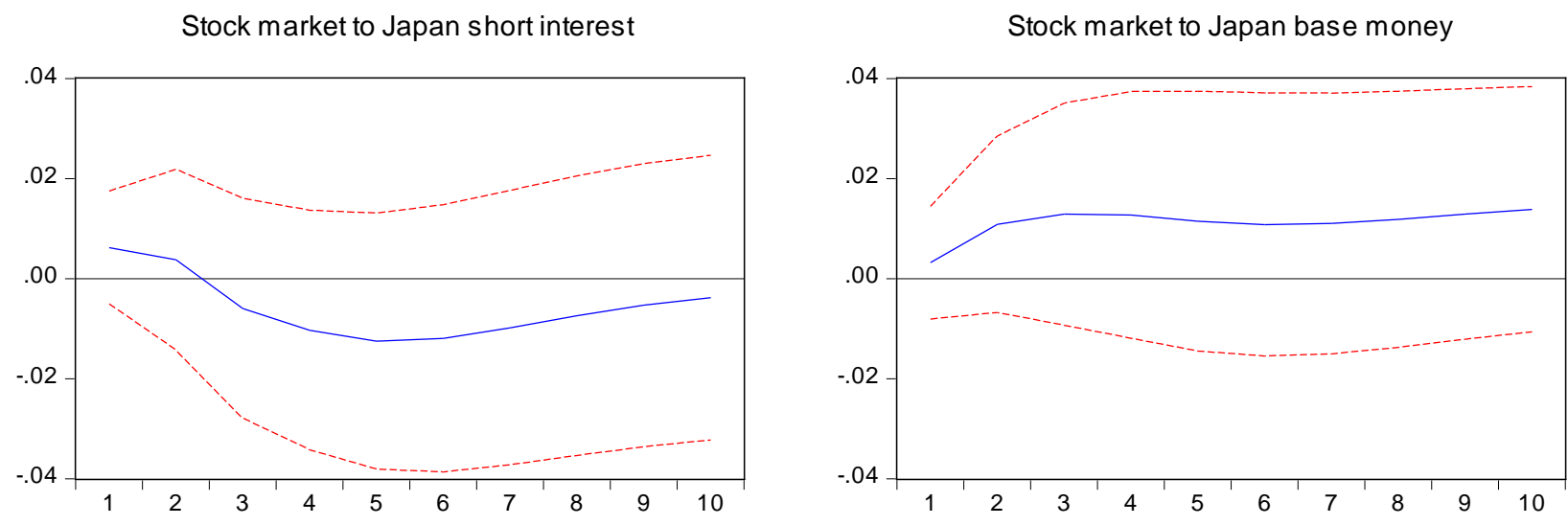

Japan long interest to Japan short interest

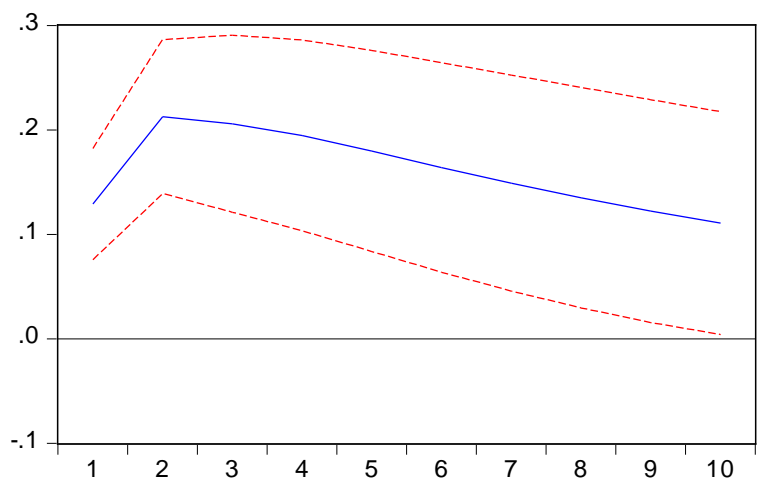

Japan long interest to Japan base money

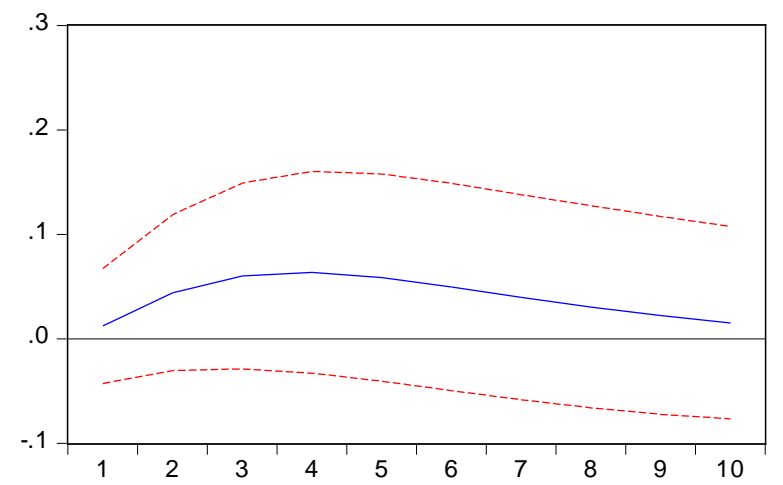




\section{Figure 11: Japan: Impulse Responses of the Japanese Output Gap and Inflation to Shocks to the Japanese Stock Market and the Long term Interest Rate}

Response to Generalized One S.D. Innovations \pm 2 S.E.
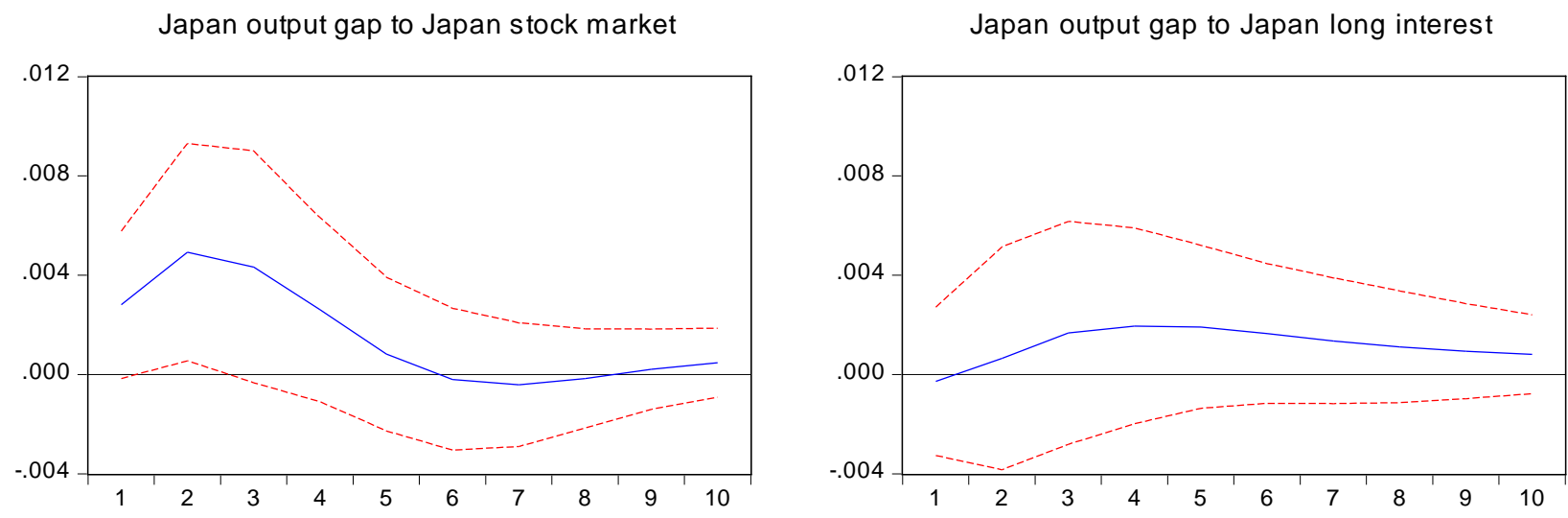

Japan inflation to Japan stock market

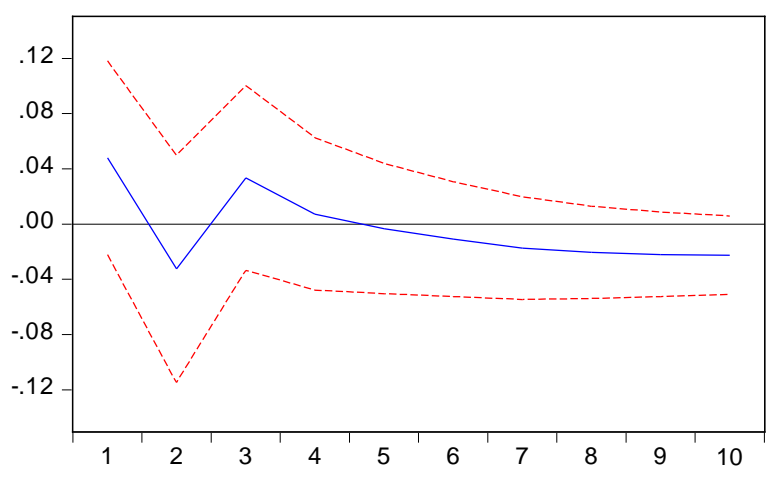

Japan inflation to Japan long interest

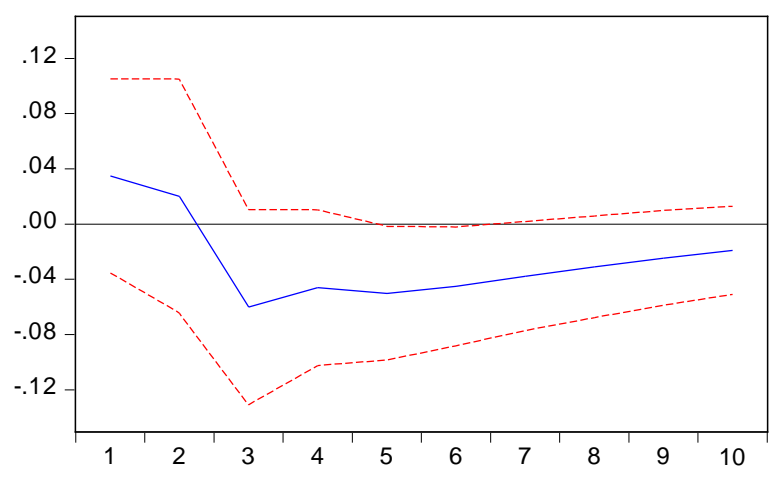

Japan inflation forecast to Japan stock market

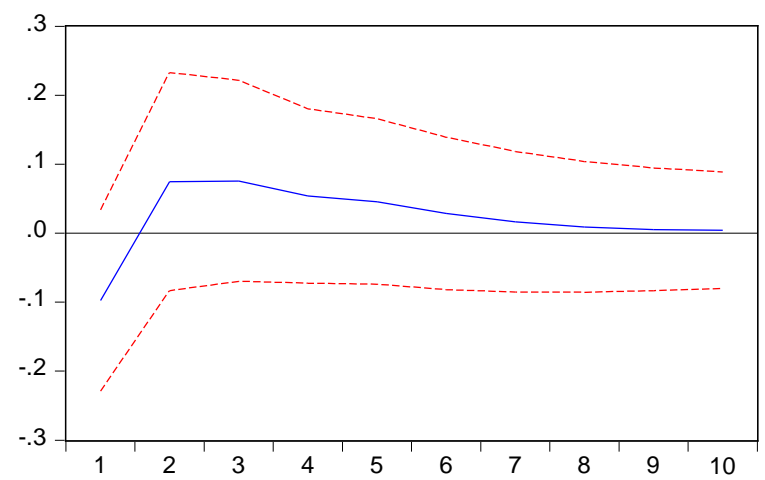

Japan inflation forecast to Japan long interest

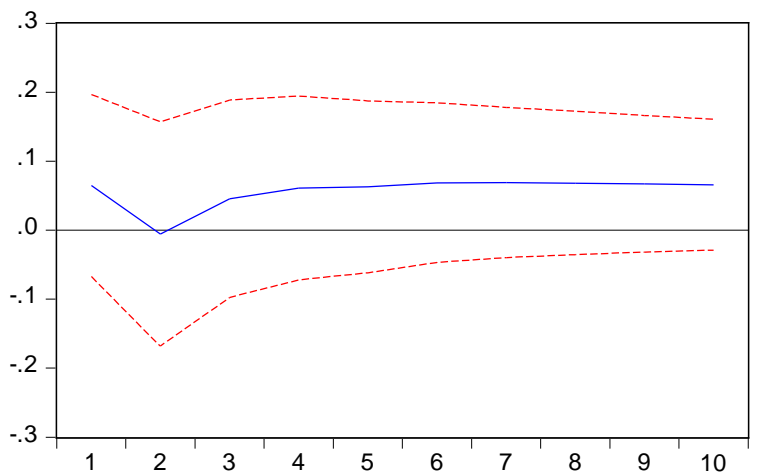


Figure 12: Japan-U.S.: Impulse Responses of the Output Gap to Short-Term Interest Rates and the Yen-Dollar Exchange Rate, 1971-2012

Response to Generalized One S.D. Innovations \pm 2 S.E.

usoutput to Yen-Dollar

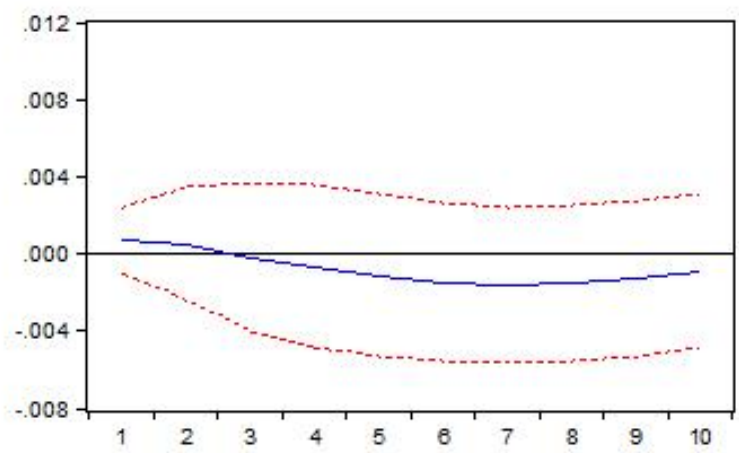

USOutput to Japlnt

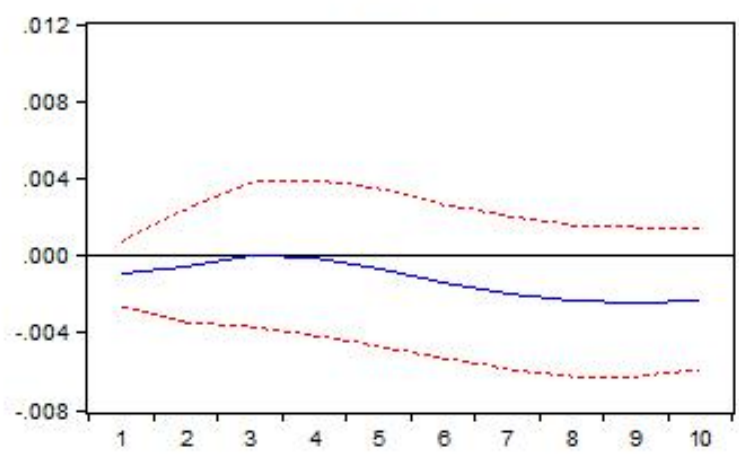

JapOutput to FedFunds

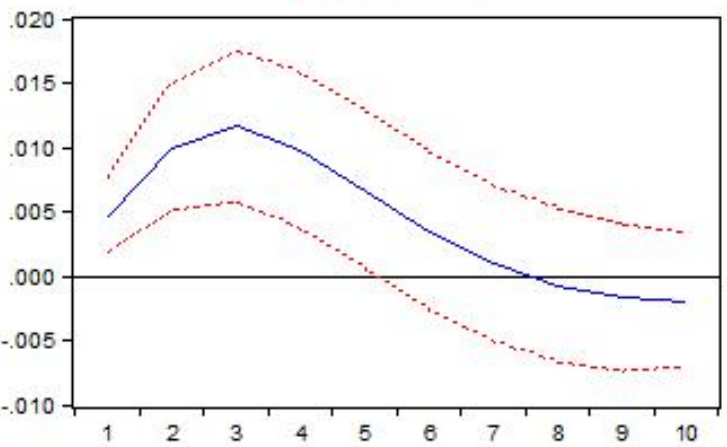

USOutput to FedFunds

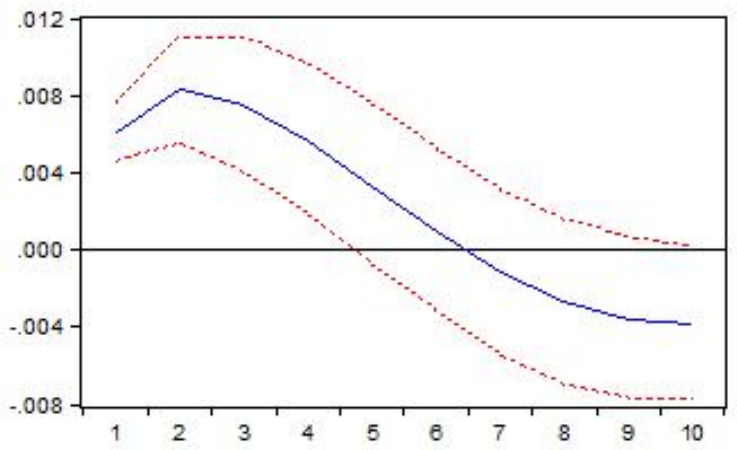

JapOutput to Yen-Dollar

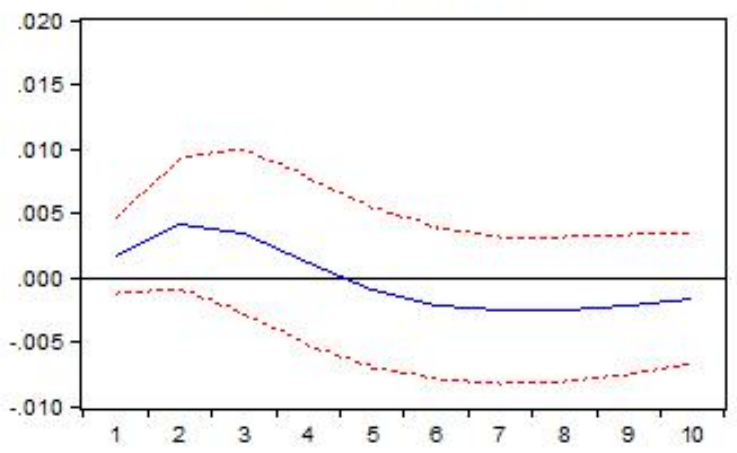

JapOutput to Japlnt

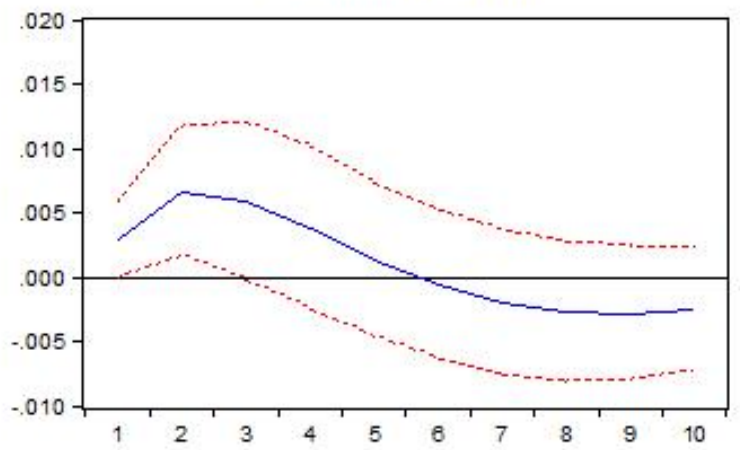


Figure 13: Japan-U.S.: Impulse Responses of the Output Gap and Yen-Dollar Rate to Base Monies, 1971-2013

Response to Generalized One S.D. Innovations \pm 2 S.E.
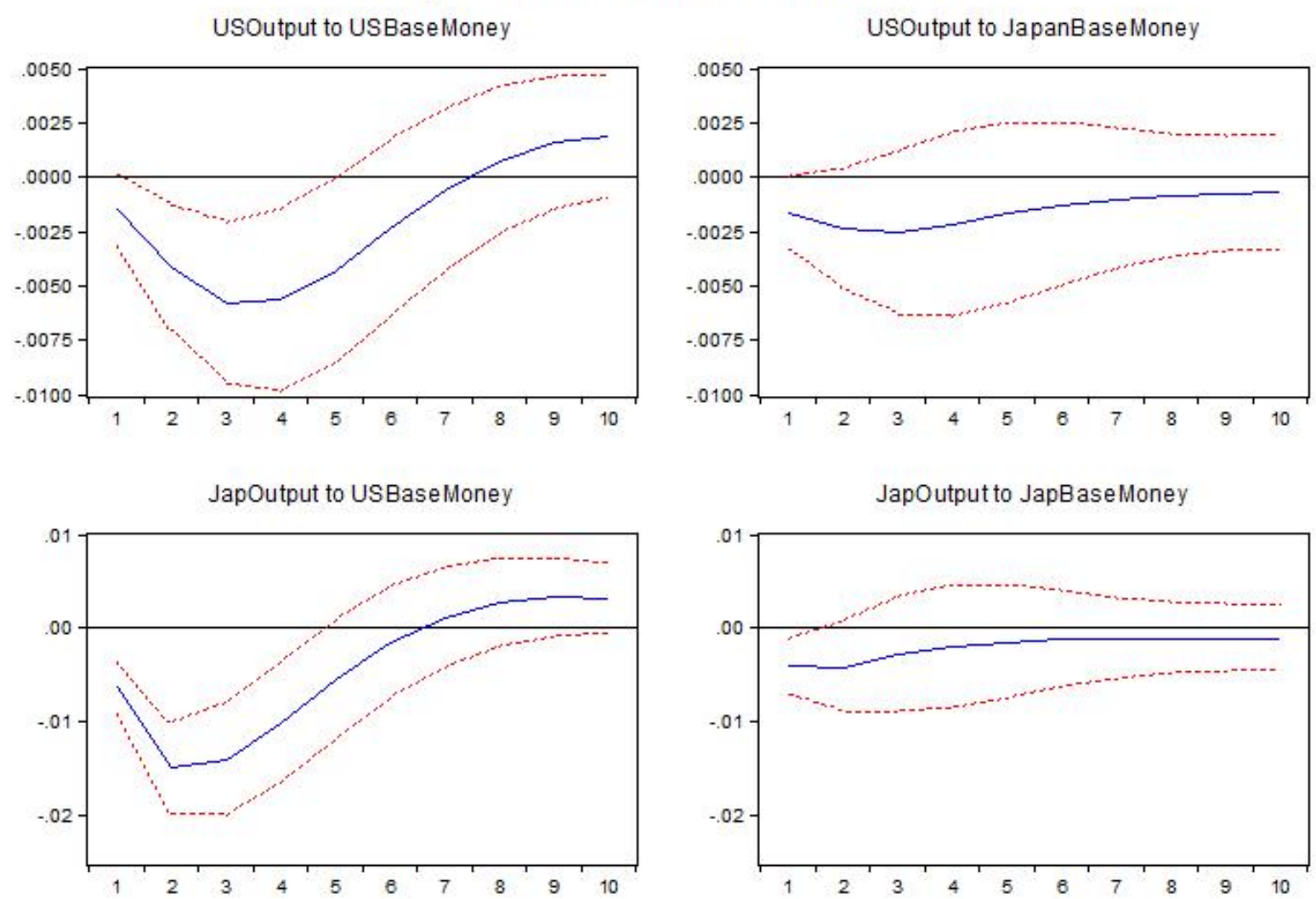

Yen-D ollar to USBaseMoney

Yen-D ollar to JapBase Money
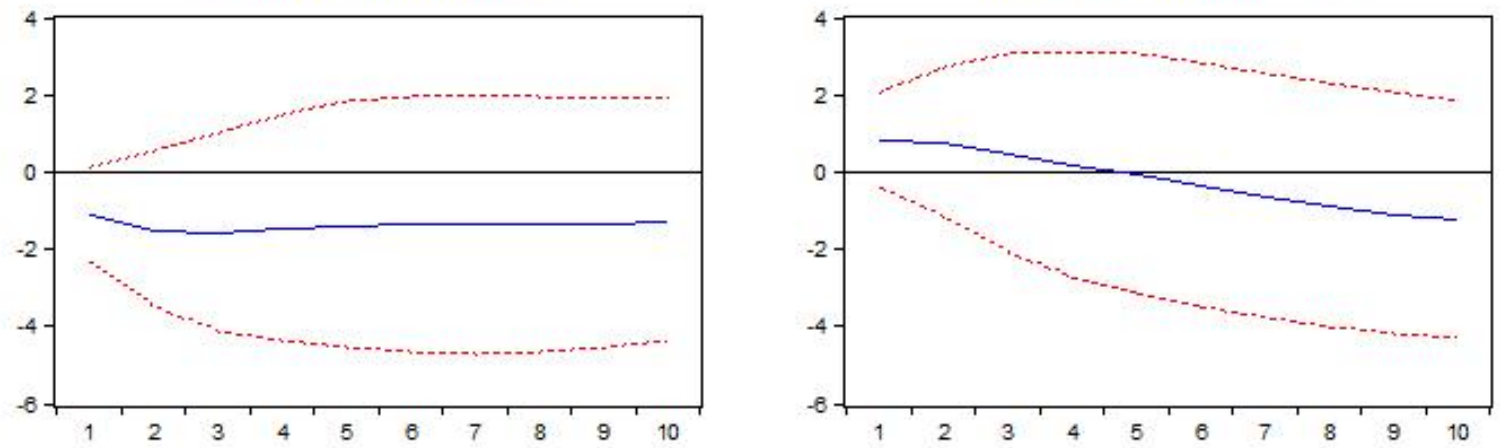
Figure 14: Japan-U.S.: Impulse Responses of the Output Gap to Short Term Interest Rates and the Yen-Dollar Exchange Rate, 1971-1999

Response to Generalized One S.D. Innovations \pm 2 S.E.

USOutput to Yen-Dollar

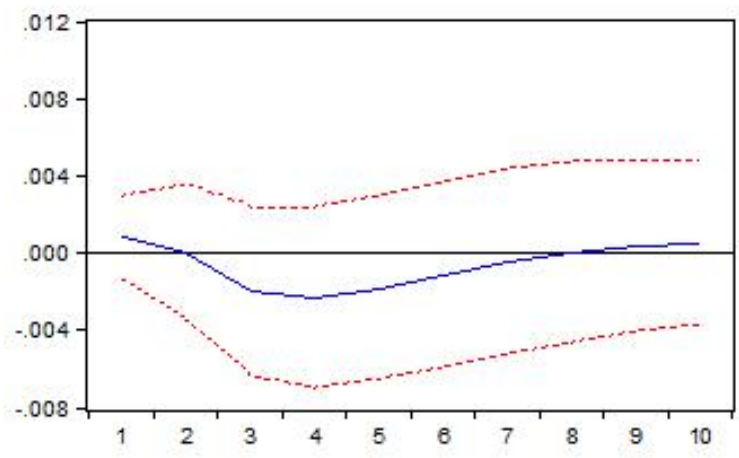

USOutput to Japlnt

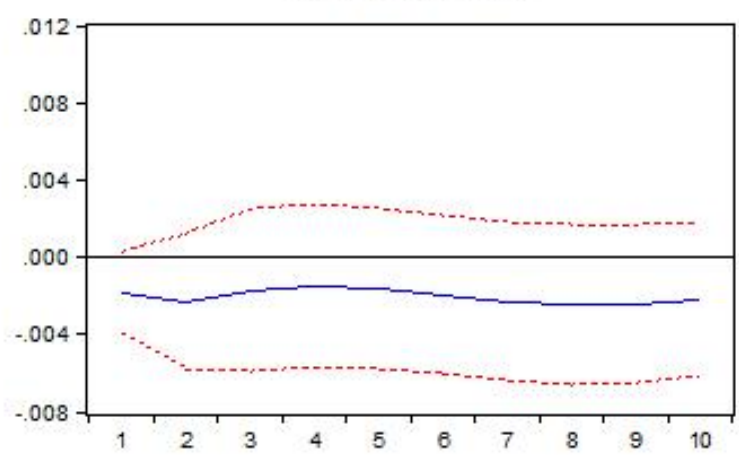

JapOutput to FedFunds

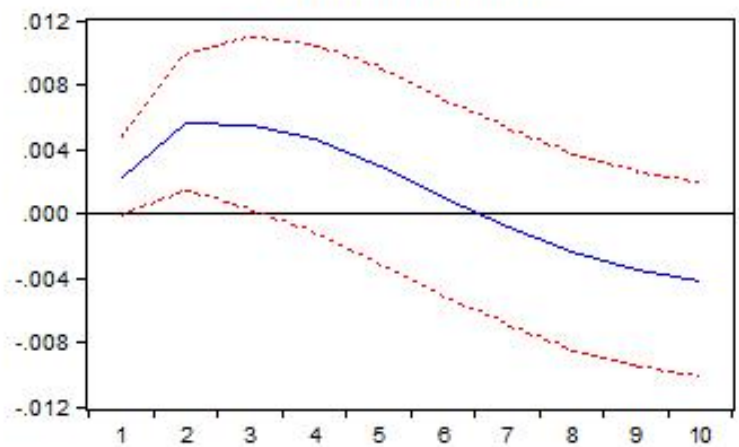

USOutput to FedFunds

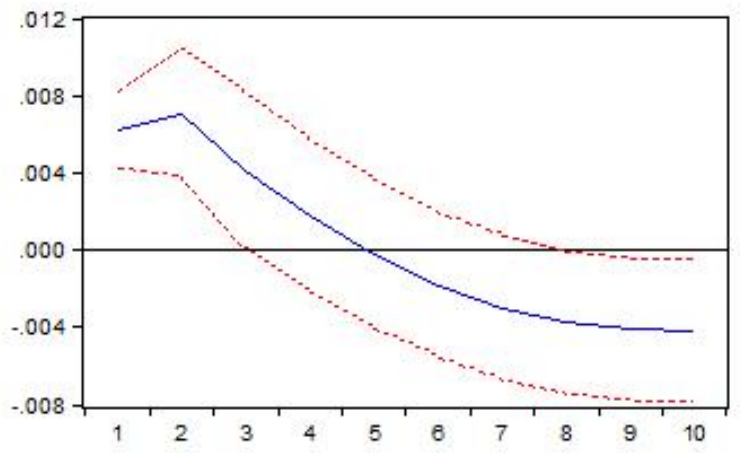

JapOutput to Yen-Dollar

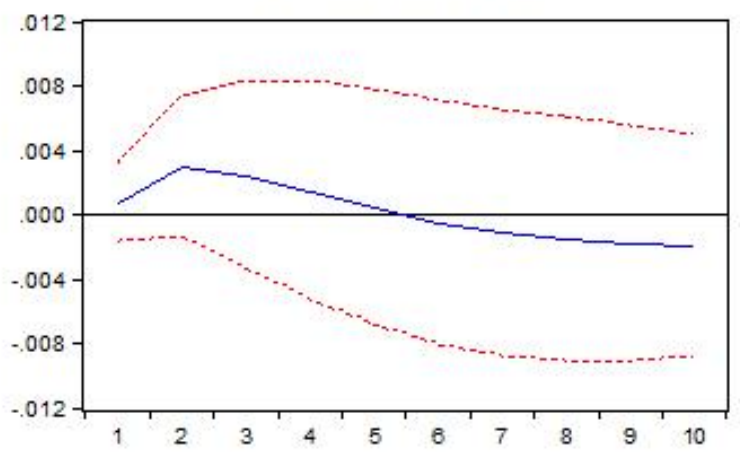

JapOutput to Japlnt

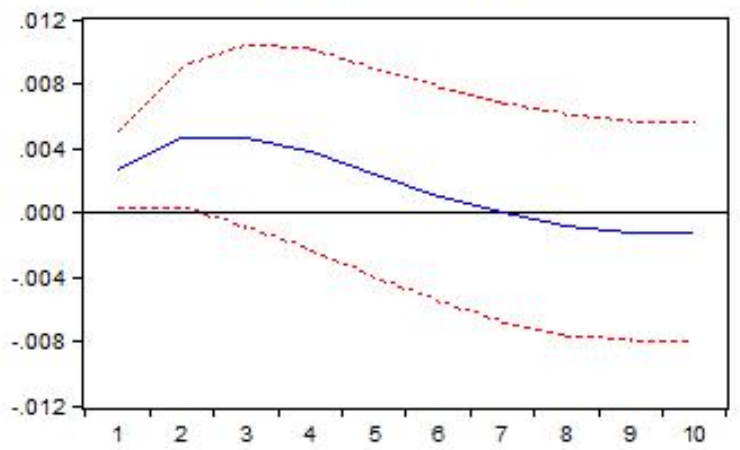


Figure 15: Japan-U.S.: Impulse Responses of the Output Gap and the Yen-Dollar Rate to Base Monies, 1971-1999.

Response to Generalized One S.D. Innovations \pm 2 S.E.

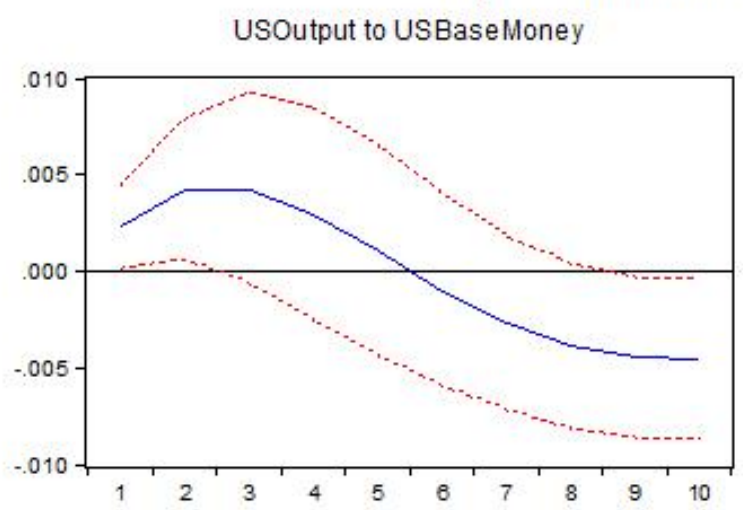

USOutput to JapBase Money
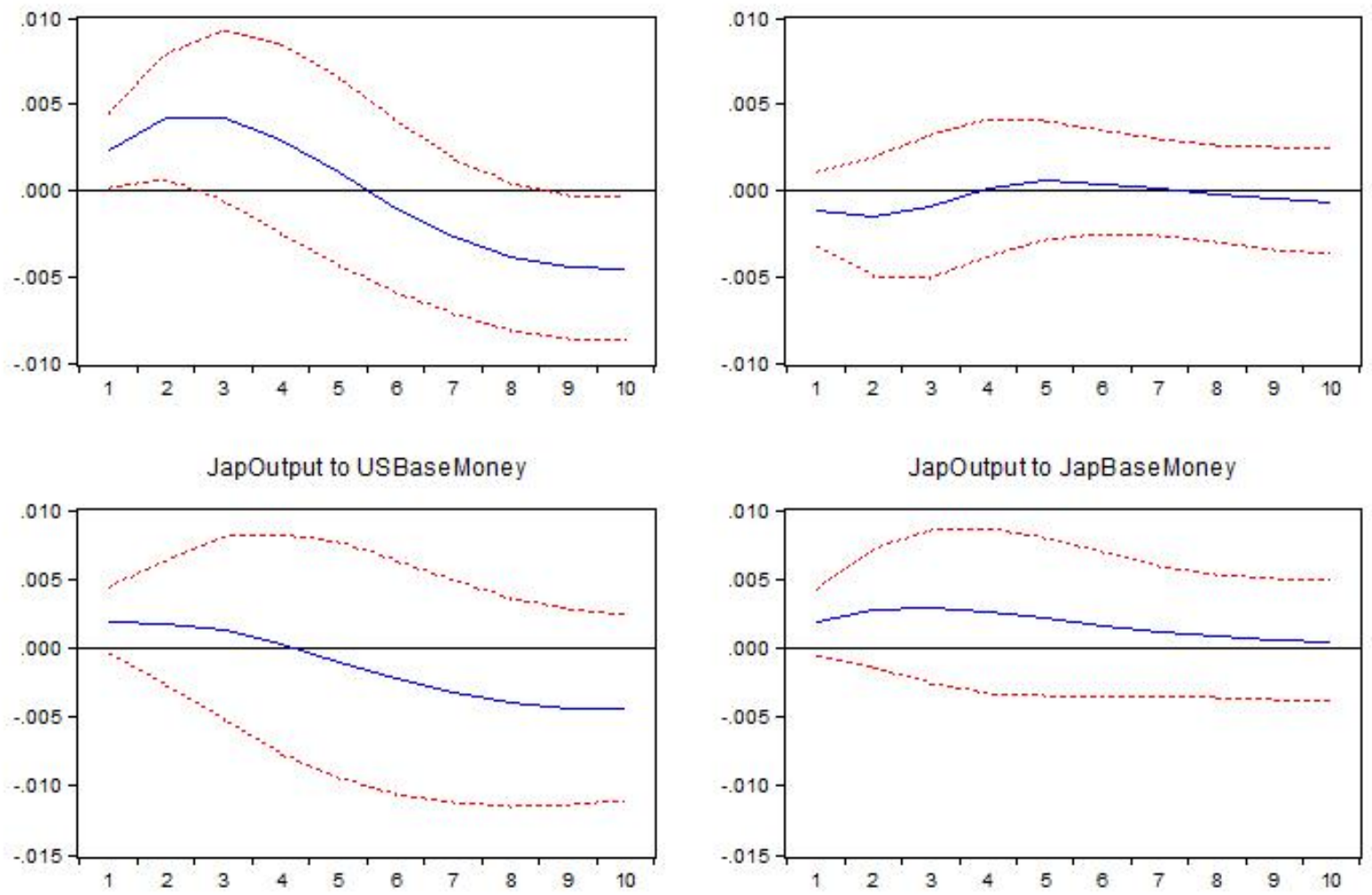

Yen-D ollar to USBaseMoney

Yen-D ollar to JapBase Money
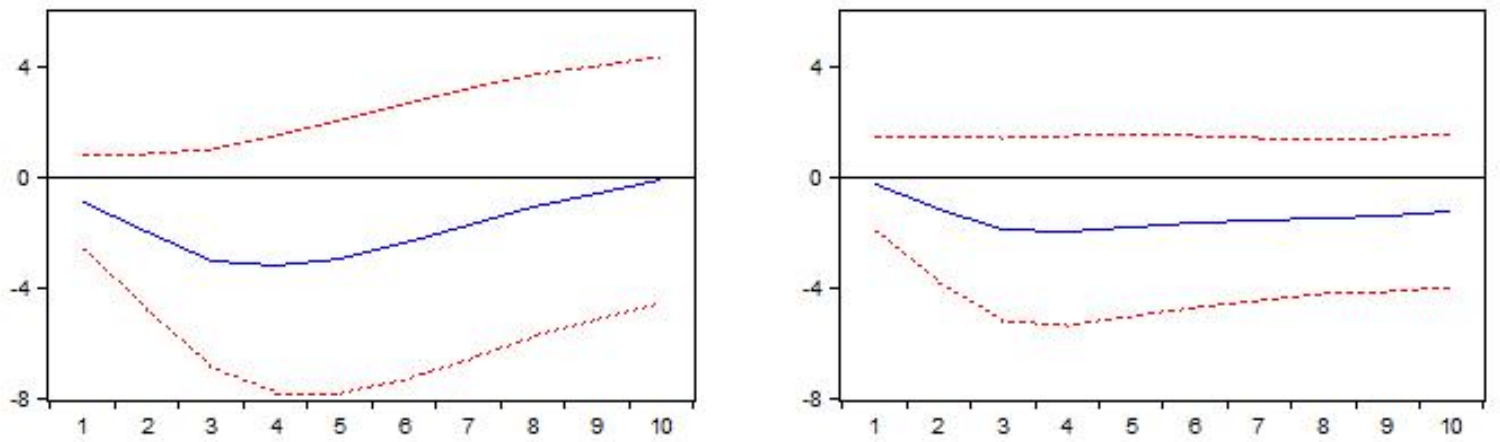
Figure 16: Japan-U.S.: Impulse Responses of the Output Gap to Short Term Interest Rates and the Yen-Dollar Exchange Rate, 1995-2013

Response to Generalized One S.D. Innovations \pm 2 S.E.

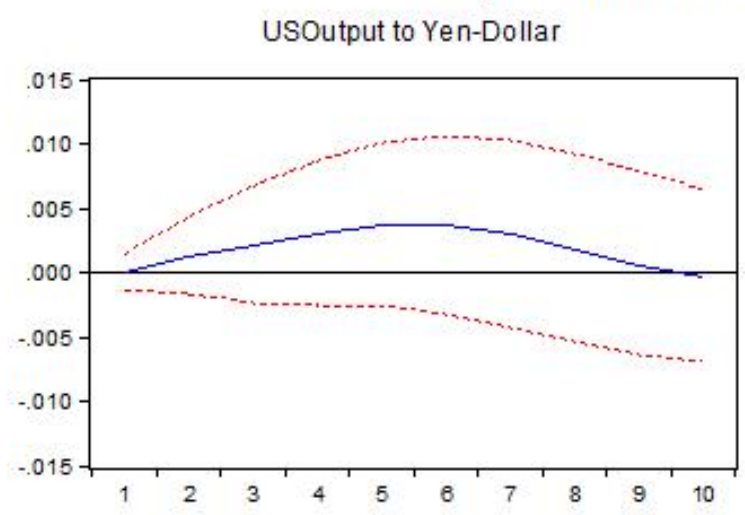

USOutput to FedFunds

USOutput to Japlnt
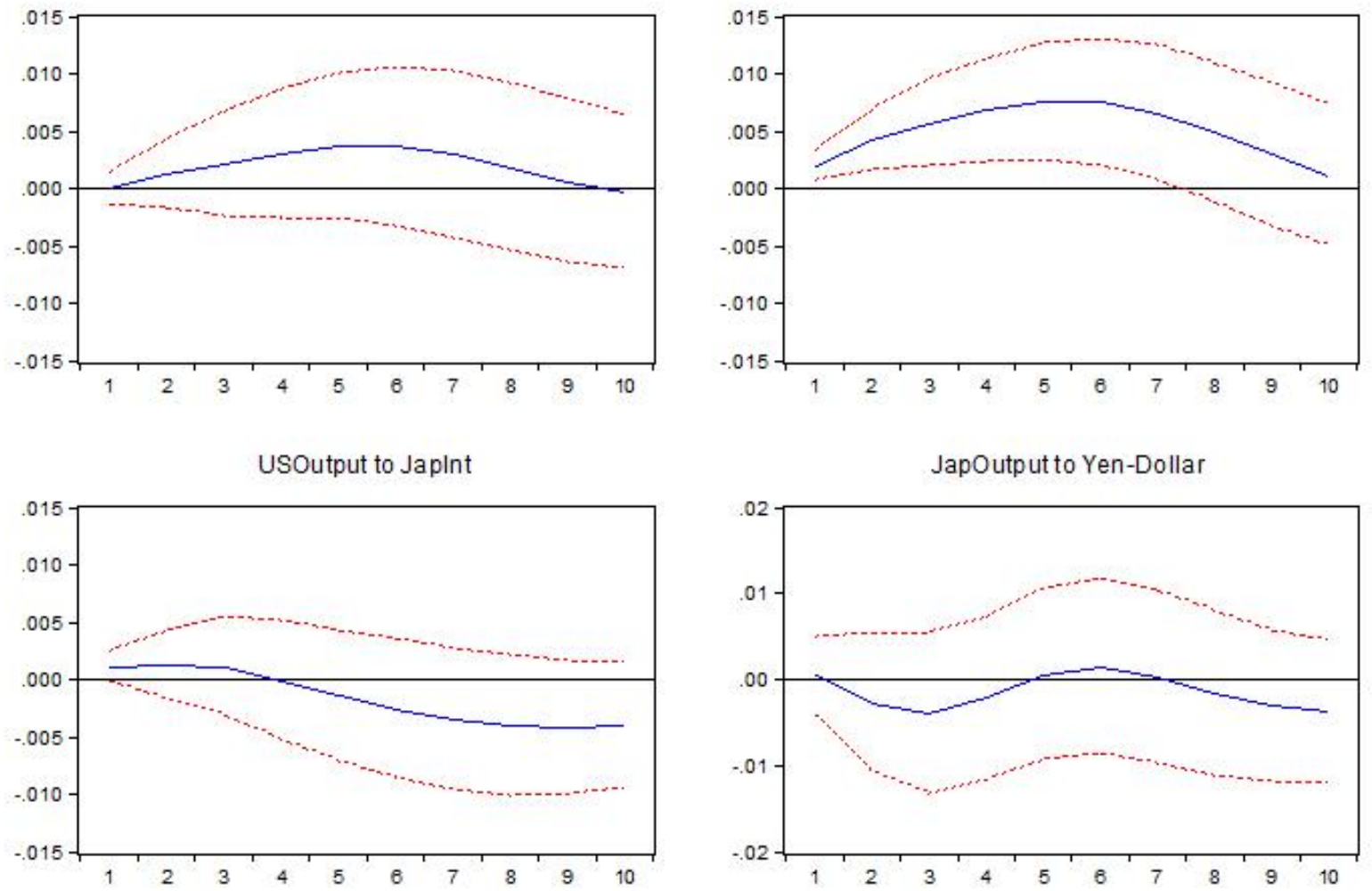

JapOutput to FedFunds

JapOutput to Japlnt
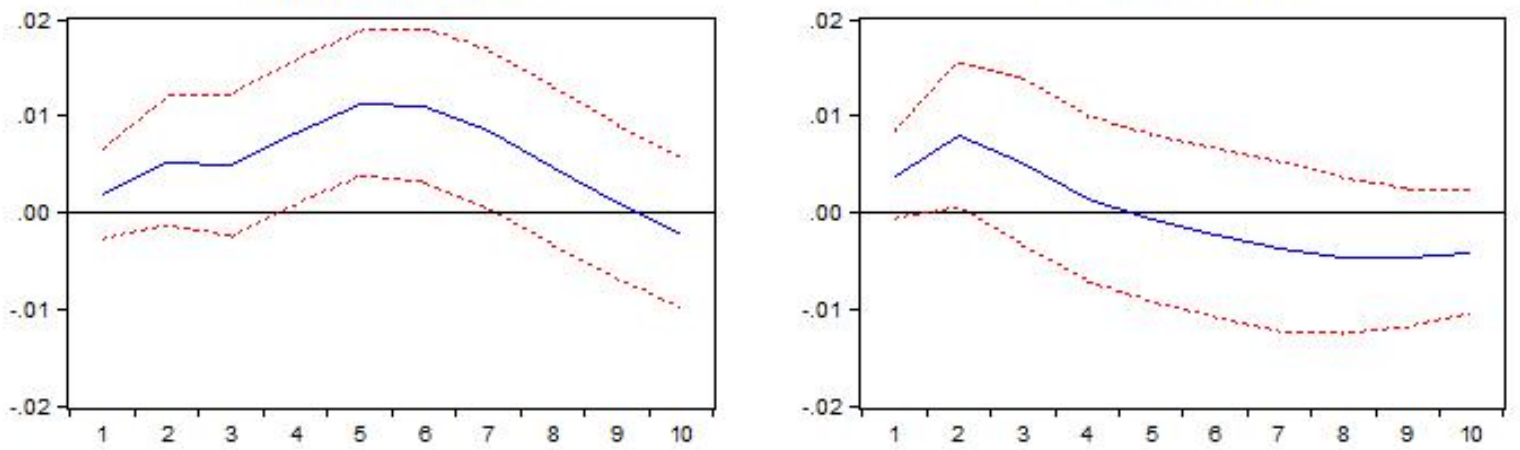
Figure 17: Japan-U.S.: Impulse Responses of the Output Gap and the Yen-Dollar Rate to Base Monies, 1995-2013

Response to Generalized One S.D. Innovations \pm 2 S.E.

USOutput to USBaseMoney

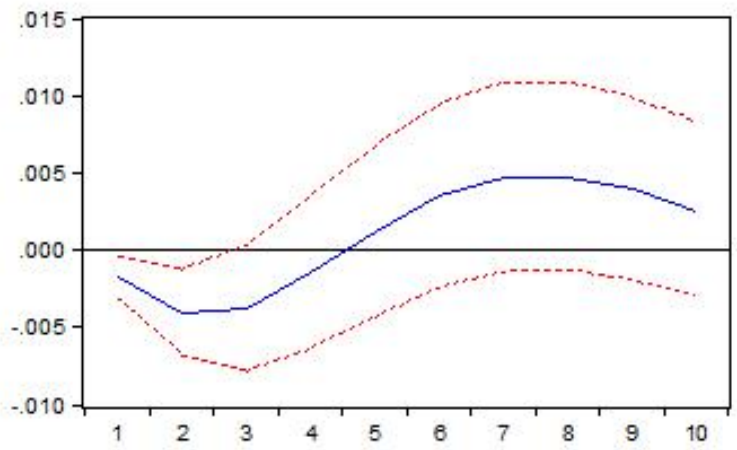

JapOutput to USBase Money

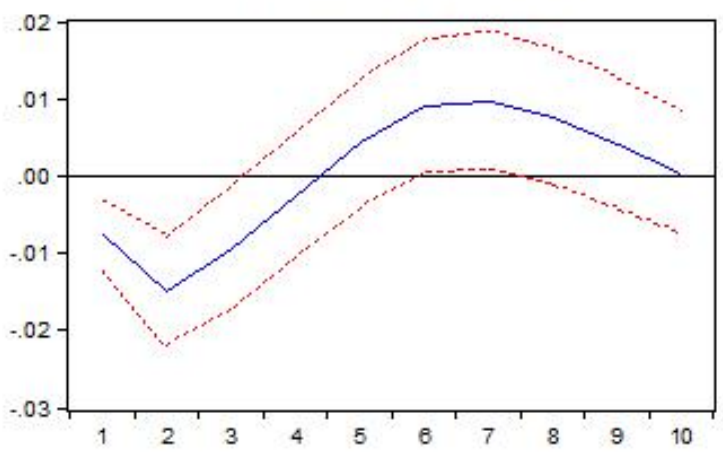

Yen-D ollar to USBase Money

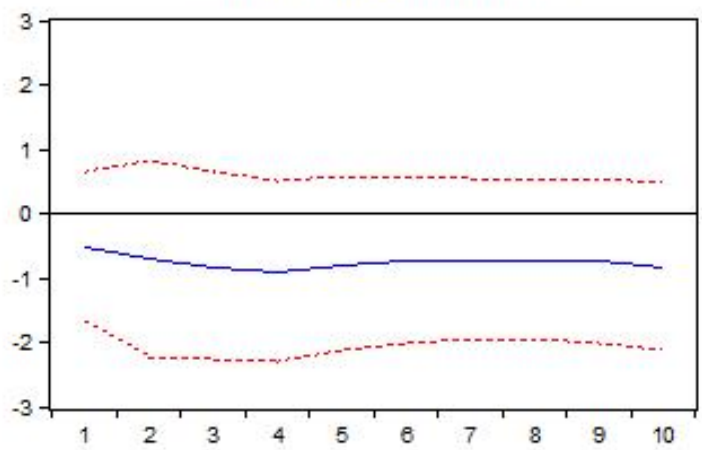

USOutput to JapBase Money

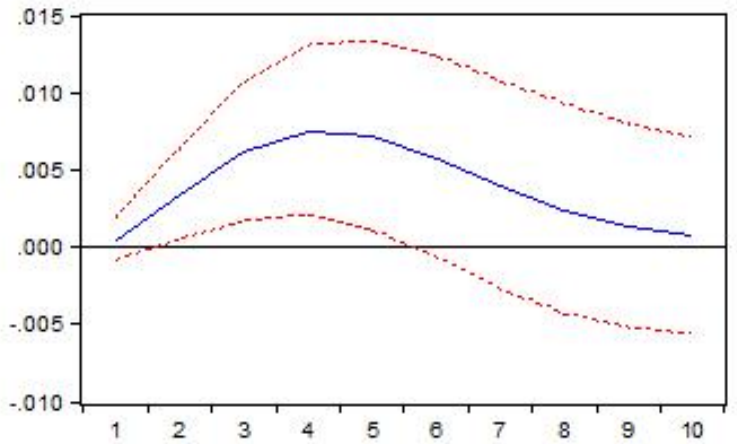

JapOutput to JapBase Money

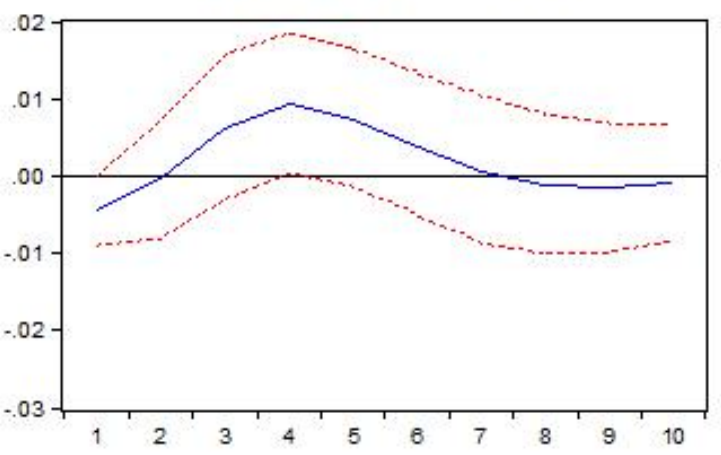

Yen-Dollar to JapBase Money

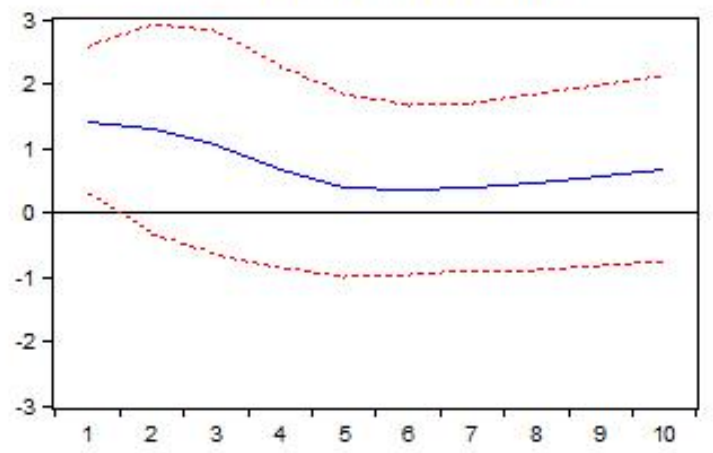


Figure 18: Impulse Responses of the Japanese Output Gap to the U.S. Output Gap and Vice Versa

Response to Generalized One S.D. Innovations \pm 2 S.E.

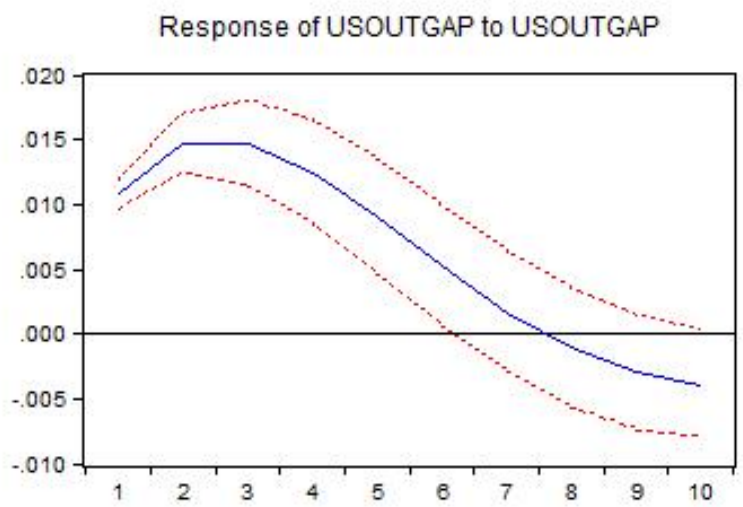

Response of USOUTGAP to JOUTGAP

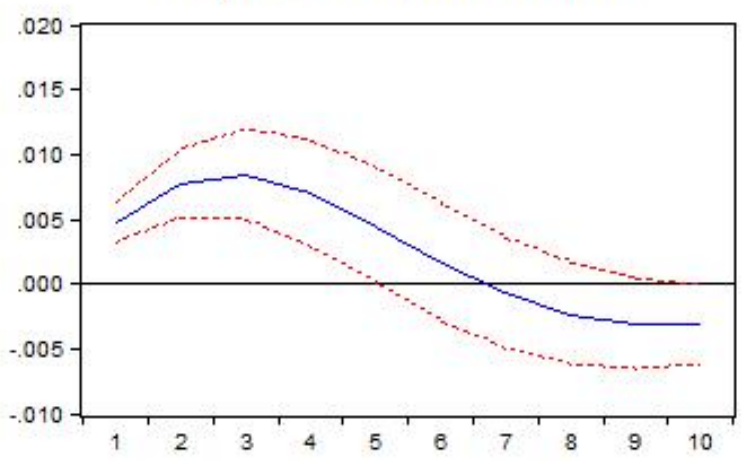

Response of JOUTGAP to USOUTGAP

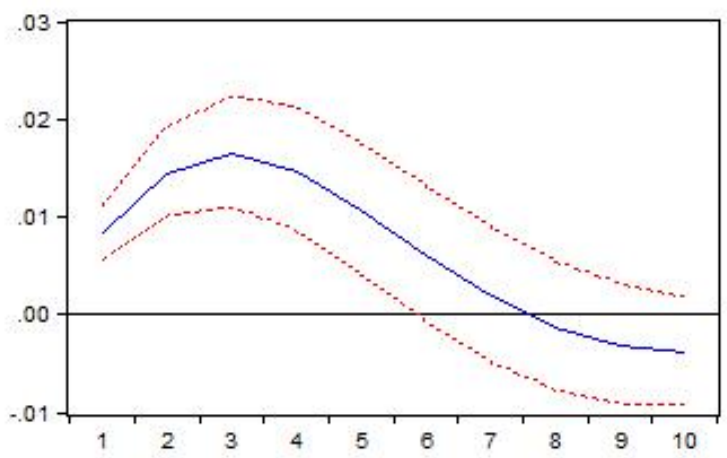

Response of JOUTGAP to JOUTGAP

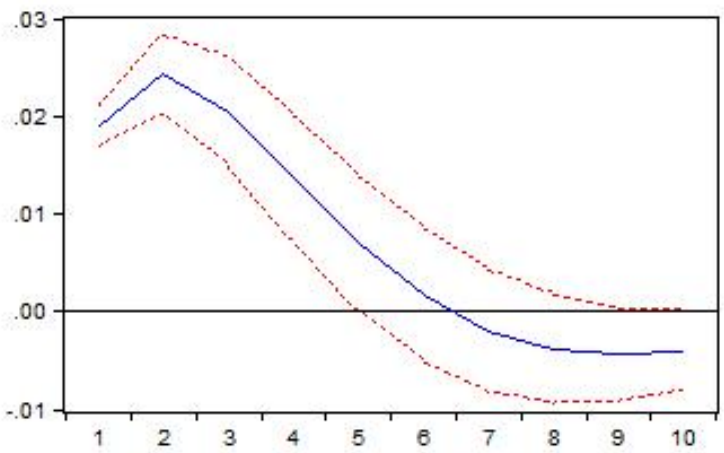


Figure 19: Impulse Responses of 1 sd yen Depreciation on the GDPs of Japan, the U.S., and the Rest of Asia.

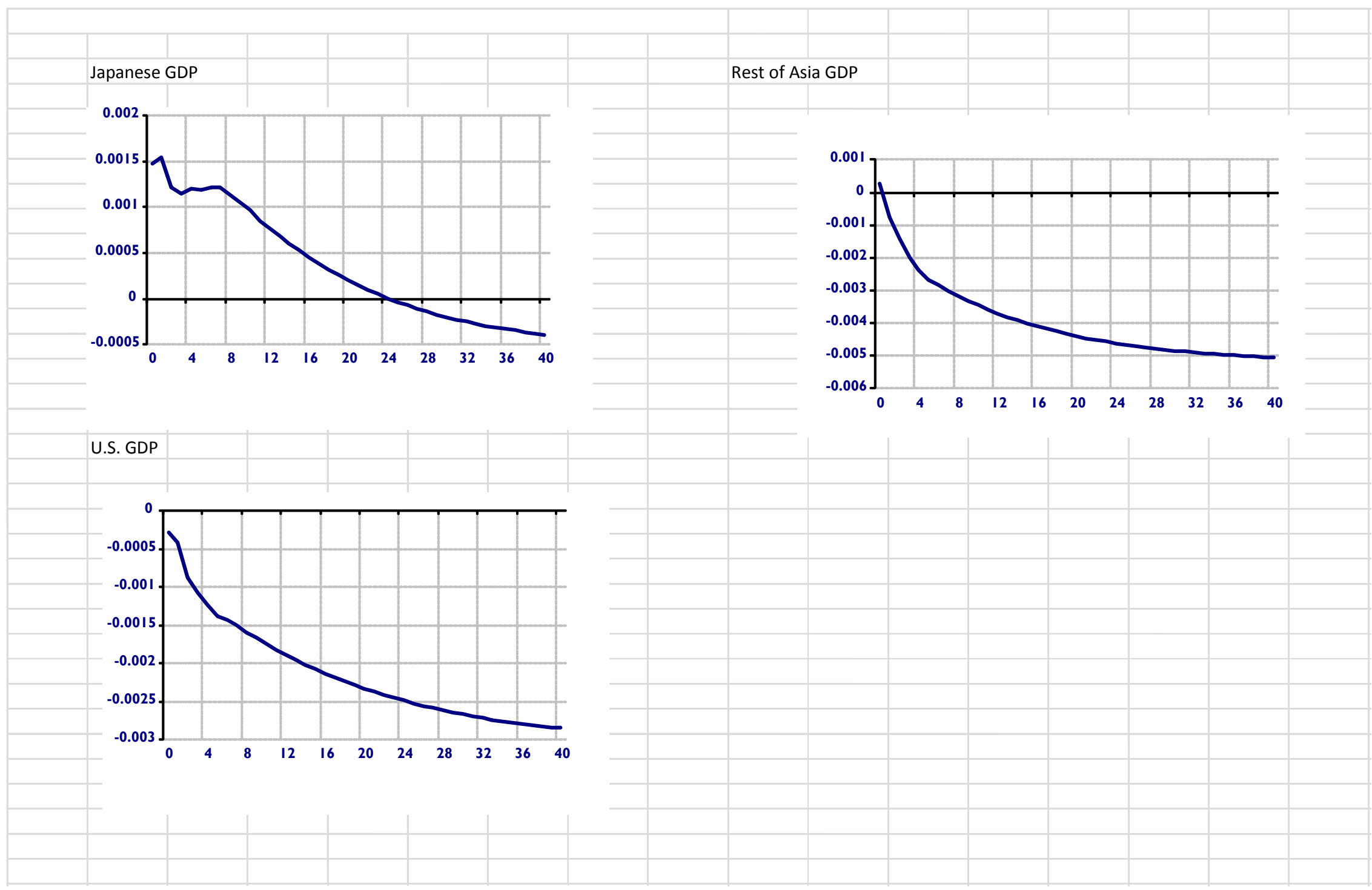


Figure 20: Impulse Responses of Shocks to Japanese GDP on U.S. and Rest of Asia GDPs

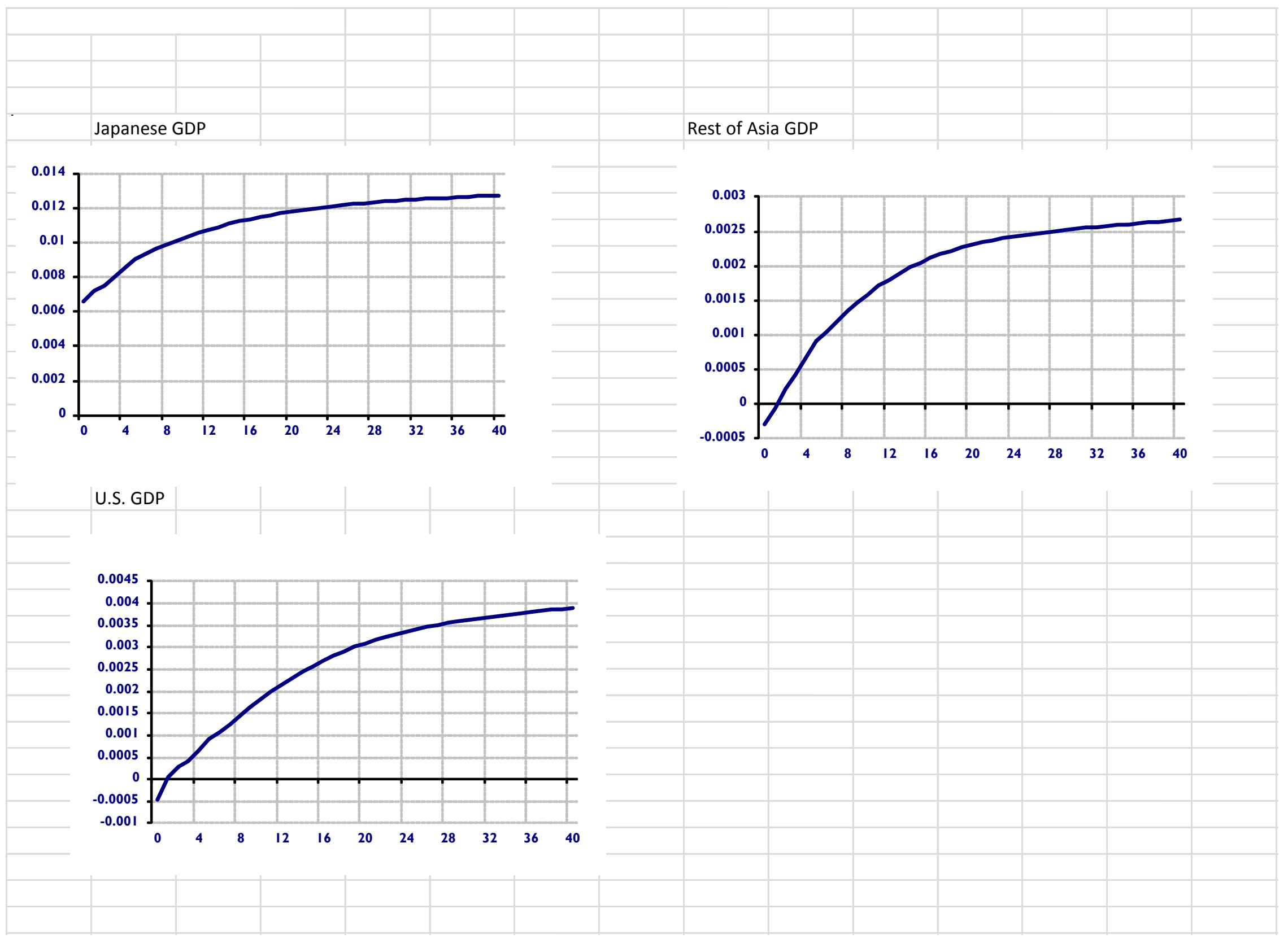

